\title{
تهيئة وتحسين زيارة مقبرة البقيع بالمدينة المنورة
}

\section{محمد عبد الله إدريس}

معهُ خادم الحرمين الثريفين لأبحاث الحج والعدة - جامعة أم القرى، مكة المكرمة، المدلكة العربية السعودية Edreesma2@hotmail.com

الدستخلص. مقبرة البقيع هي المقبرة الرئيسة لأهل المدينة المنورة. ويضم البقيع رفات الآلاف المؤلفة من أهل المدينة المنورة ومن

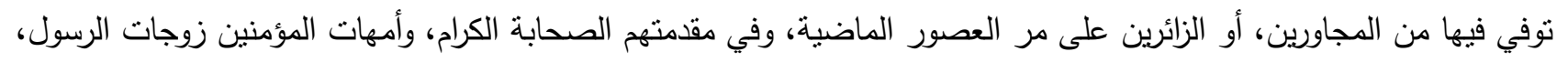

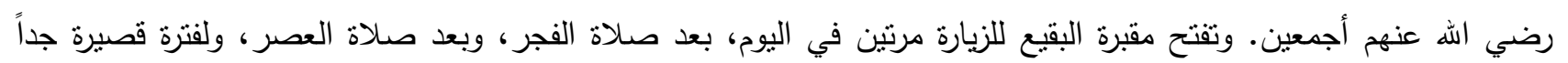

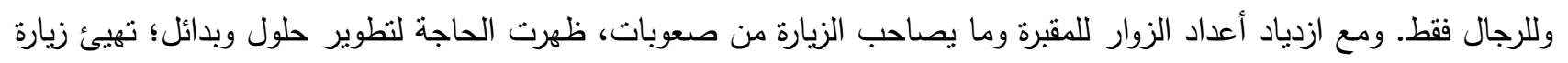

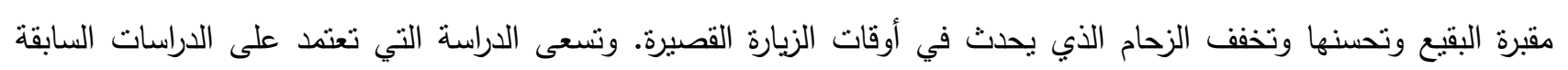

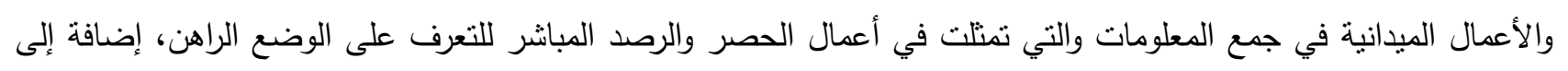

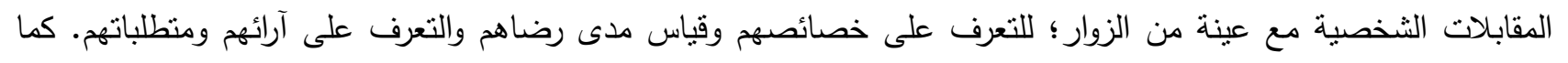

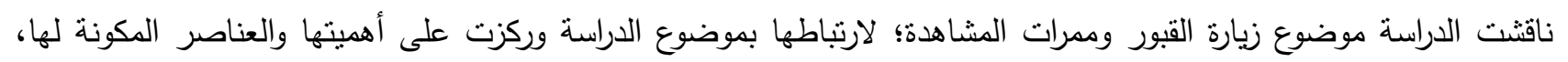

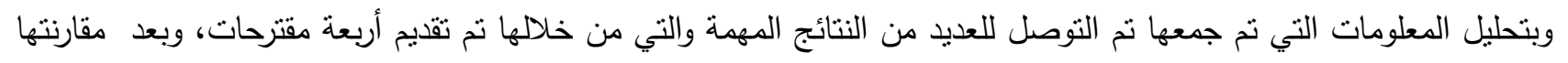

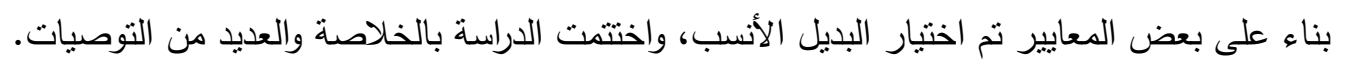
كلمات مفتاحية: المدينة المنورة، البقيع، الزيارة، تهيئة، تحسي.

ومقبرة البقيع هي المقبرة الرئيسة لأهل المدينة المنورة

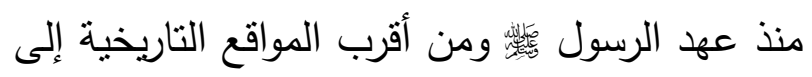
المسجد النبوي، ويضم البقيع رفات الآلاف المؤلفة

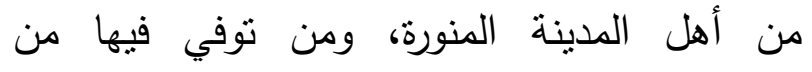

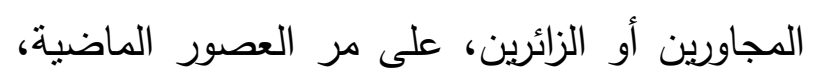

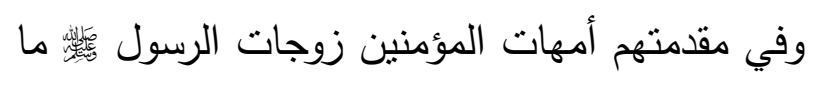

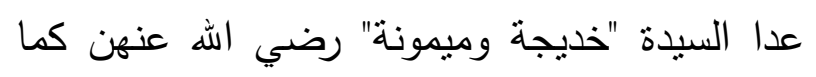

\section{1- المقدمة}

البقيع: هو البقعة من الأرض واحدة البقاع، وهو

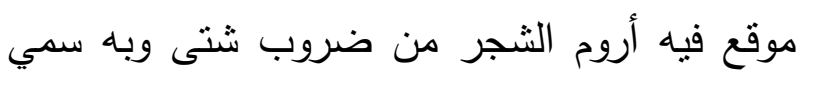

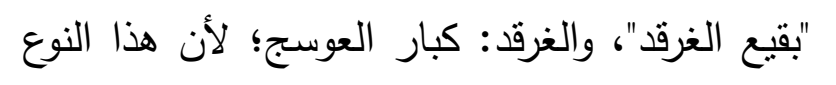

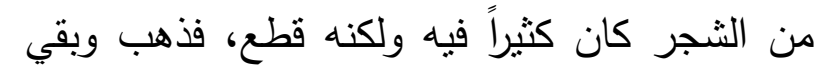

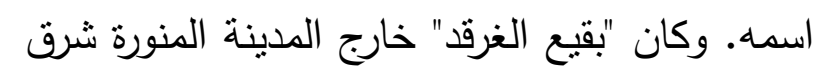

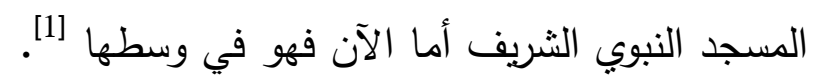




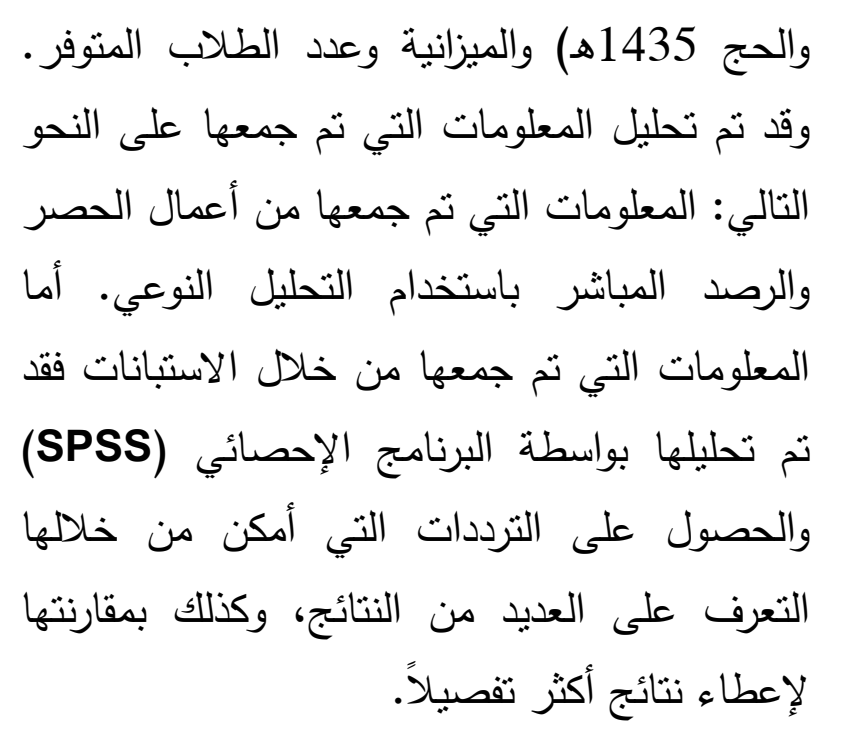

1-2 خطة العقل

وبناء على طبيعة الدراسة ومنهجيتها ولتحقيق غايتها فقد تم تقسيم خطة العمل على النحو النالي: لمرحلة الأولى: مراجعة الدراسات السابقة

المتعلقة بموضوع الدراسة.

المرحلة الثانية: الأعمال الميدانية والتي

تتقسم إلى جزئين: الجزء الأول ويهتم بالتعرف على الاعلى التهاليه

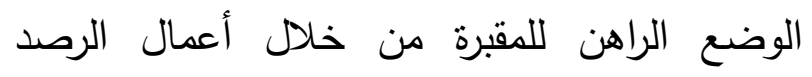

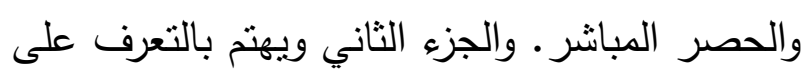
آراء المستخدمين من خلال استبانة تم تصميمها لهذا الغرض، وقد تم ذلك خلا شهري رمضان والحج واللذين يشهدان كثافة عالية للزوار .

المرحلة الثالثة: استخلاص أهم النتائج بعد

تحليل المعلومات التي نم جمعها من المعلومات الميدانية والاستبانات التي تم توزيعها في موسمي تمعي تمني

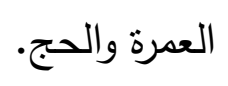

دفن فيها ابنته "فاطمة الزهراء" وابنه "إبراهيم "وعمه

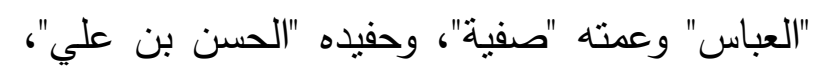
و"ذو النورين عثمان بن عفان"، والسيدة "رقية وأم كلثوم"، والصحابة الكرام "رضي الله تعالى عنهم أجمعين". وتفتح مقبرة البقيع للزيارة مرنين في اليوم وذللك بعد صلاة الفجر ، وبعد صلاة العصر ، ولفترة

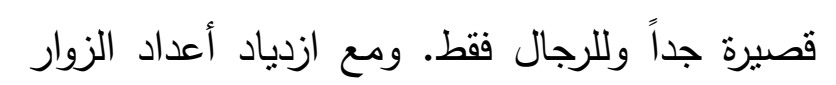
أصبحت أوقات الزيارة تشهد ازدحاماً شديداً، وتكدساً

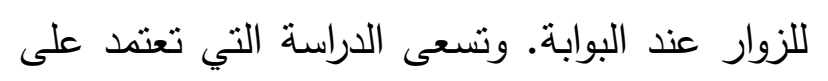
الدراسات السابقة، والمعلومات الميدانية، إلى تهيئة

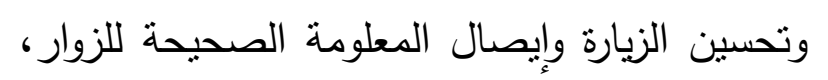
وذللك من خلا: التعرف على الوضع الراهن للمقبرة والزيارة، وقياس آراء المستخدمين واحتياجاتهم، وتقديم الحلول والمقترحات المناسبة التي تساعد في تسهيل

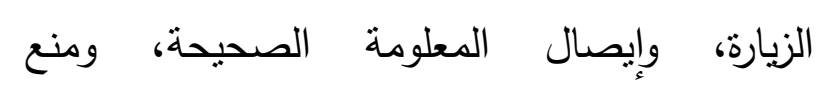
التصرفات الخاطئة.

1-2 - 2 منهجية الدراسة

حيث إن غاية الدراسة تهيئة وتحسين الزيارة،

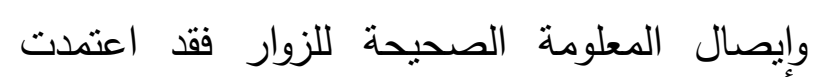

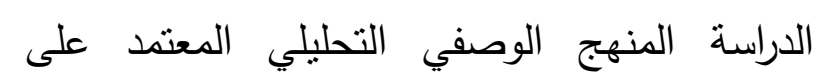

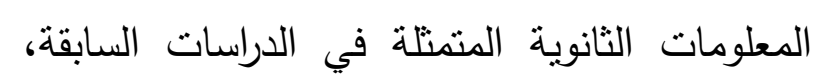

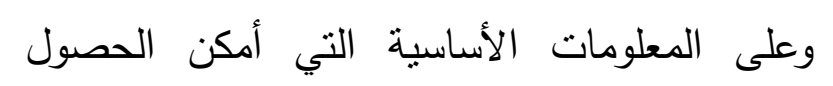

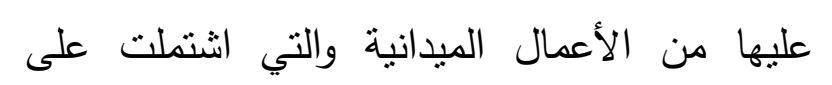

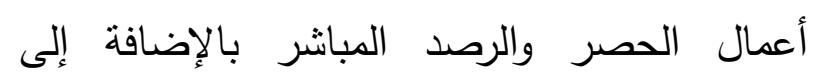
المقابلات الثخصية للزوار، حيث تم توزيع 456

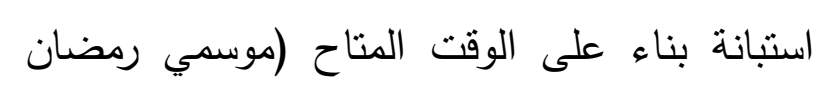


- الاقتداء بالنبي -

السلام، يكسب المسلم بها أجر الاقتداء به، وأجر

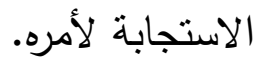

- الإحسان إلى إخوانه المسلمين بالدعاء لهم،

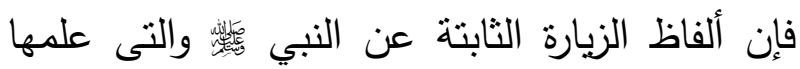

أصحابه تتضمن الدعاء للموتى من المسلمين، وذلك

$$
\text { نافع لهم. }
$$

\section{2-1- نيارة البقيع}

يشرع لمن زار المدينة النبوية زيارة البقيع

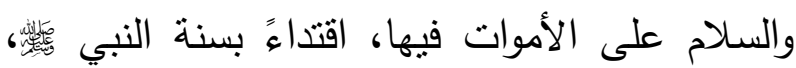
فعن عطاء بن يسار عن عائشة "رضي الله عنها"

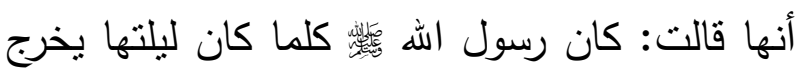
من آخر الليل إلى البقيع فيقول: السلام عليكم دار قوم مؤمنين، وأتاكم ما توعدون، غداً مؤجلون، وإنا

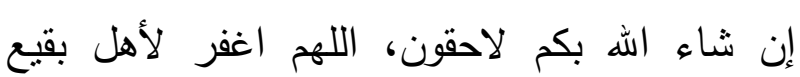
الغرقد [2]

تُقتَح مقبرة البقيع للزيارة يومياً بعد صلاة

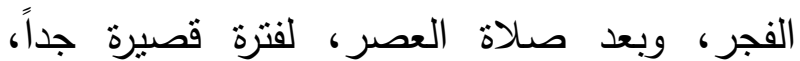
وللرجال فقط، وكان الأمر مقبولاً قبل تركيب بابين على درج الطلوع أو النزول من البقيع، وتقفل الآن

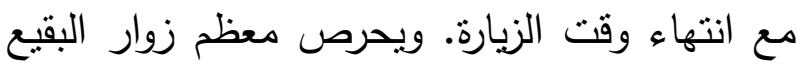
من الزائرين للمدينة المنورة على زيارة البقيع؛ لزيارة

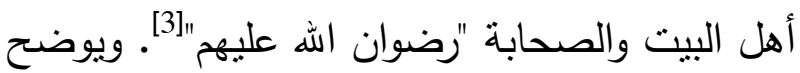
الثكل 1 أماكن بعض المقبورين فيه من أهل البيت
المرحلة الرابعة: تقديم مجموعة من الحلول

والمقترحات ومقارنتها بناء على عدد من المعايير التي تساعد على اختيار البديل الأنسب ودعمه بالرسومات التفصيلية التي توضح فكرة المقترح. 2- - 2يارة القبور

زيارة القبور سنة مؤكدة، فقد كان القبور ويقول: "زوروا القبور فإنها تذكركم الآخرة". وكان لِّ

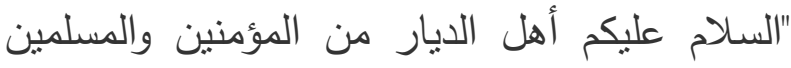
وإنا إن شاء الله بكم لاحقون، نسأل اله لنا ولكم العافية"، فالسنة للرجال أن يزوروا القبور ؛ لأنها تذكر لهاء لهاء لهان الآخرة, وتذكر الموت وتعين على الاستعداد للآخرة، لـانه

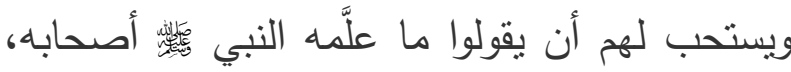
ولكن لا يقولوا هجراً، يعني: لا يقولون كلاماً سيئًا,

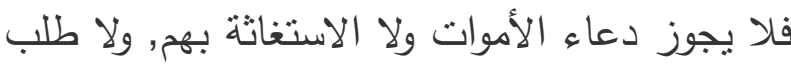

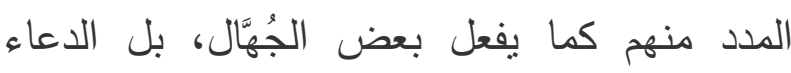
يختص بالله وحده فهو الذي يُدعى ويُسأل، والميت بهـي

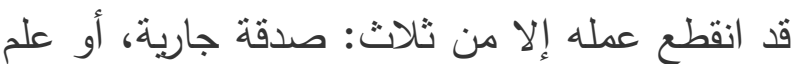
ينتفع به، أو ولد صالح يدعو له، فلا يجوز دعاؤه.

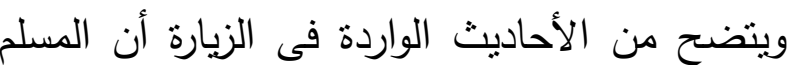
يستقيد من زيارة القبور ثناث فوائد [2]: - تذكر الموت؛ فيستعد بالعمل الصالح؛ لقوله لف 
الششاهدة في جزيرة ستاثتن بمدينة نيويورك الأمريكية نموذجاً لمر (North shore waterfront) الششاهدة المتكامل (شكل 3). ومن أهم وظائف

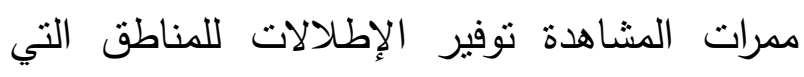

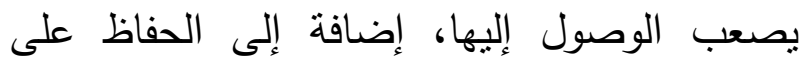

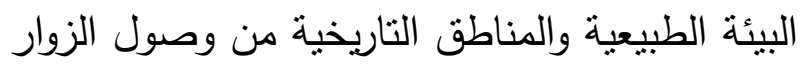
إليها لحمايتها من السلوكيات السلبية مع إتاحة ولئه الفرصة لهم للتعرف عليها والتقاط الصور التذكارية لها، وتختلف أنتكال ومواد البناء في هذه الممرات

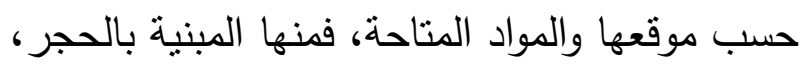
وأخرى بالخشب خصوصاً في المناطق الطبيعية والغابات، كذلك هناك المبنية بالهياكل الحديدية والخرسانة المسلحة. وقد يكون من المناسب استخدام

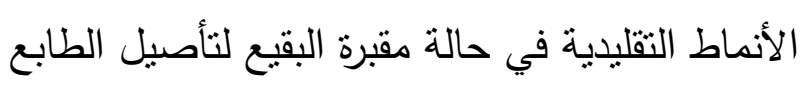
العمراني للمدينة المنورة، حيث جاءت عملية تطوير المنطقة المركزية في إطار الحفاظ على هوية المدينة
وعلى الرغم من أن الثرفة العلوية من الجهة الغربية للمقبرة (شكل 2) تمكن الزوار من مشاهدة

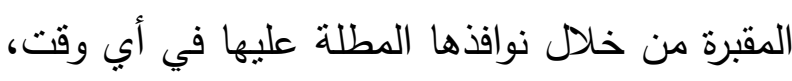
إلا أن إغلاق البوابتين المؤديتين إليها يعطل ذلك.

\section{3- ممرات المشاهدة}

حيث إن الدراسة تنتاول موضوع تهيئة وتحسين زيارة مقبرة البقيع، وبما أن ممرات المشاهدة

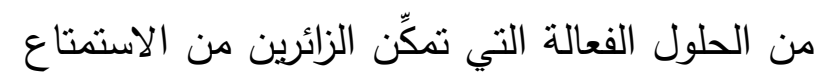

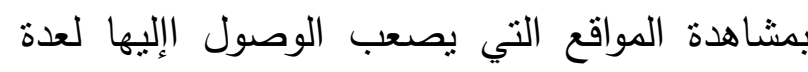

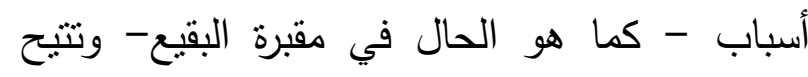
الفرصة للزيارة لفترات طويلة وفي أوقات مختلفة،

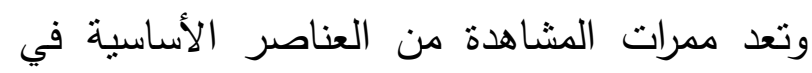

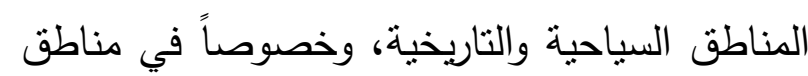

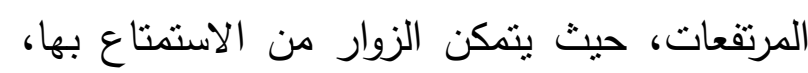
والتعرف على عناصرها، والأمتلة على ذلك متعددة

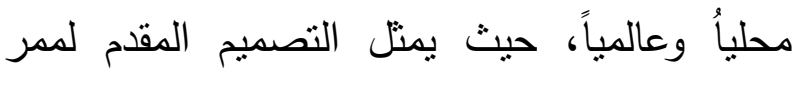

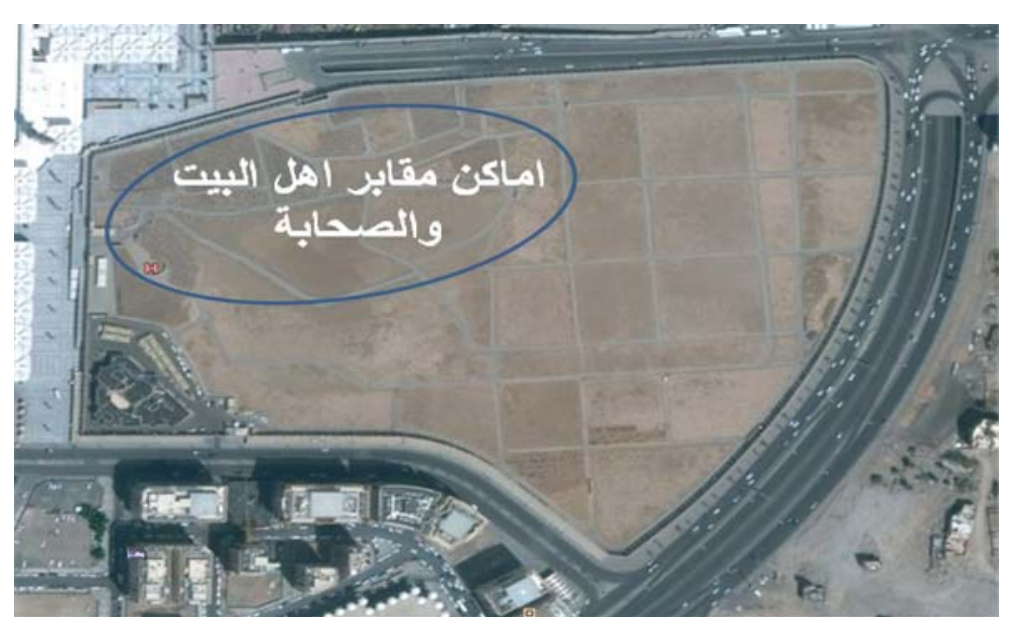

شكل 1. خريطة توضح منطقة الدراسة. 


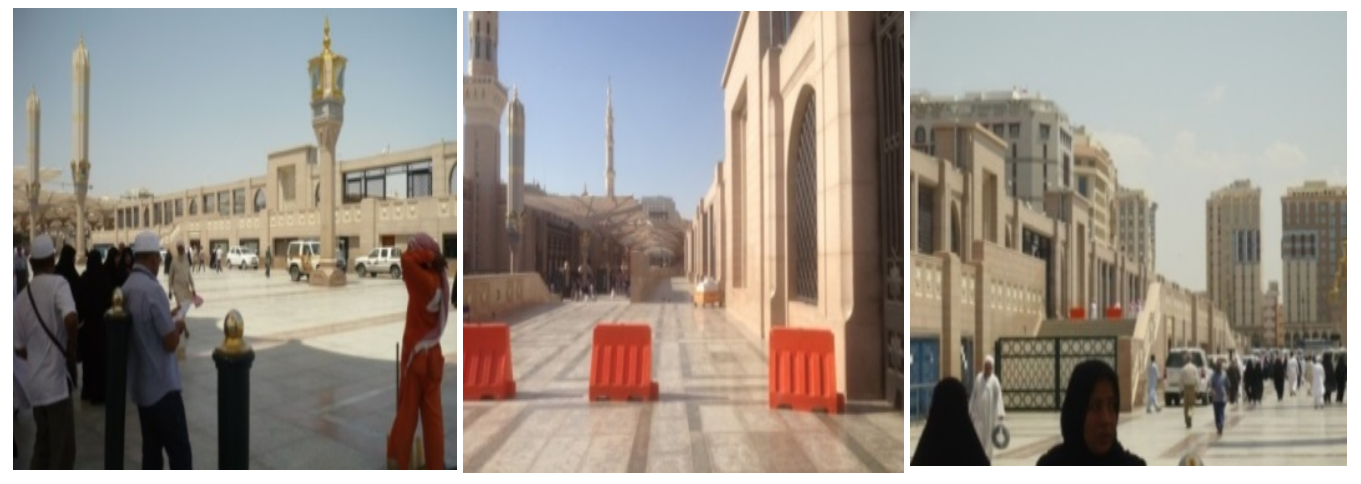

شكل 2. الساحات المحيطة بالبقيع (الباحث).

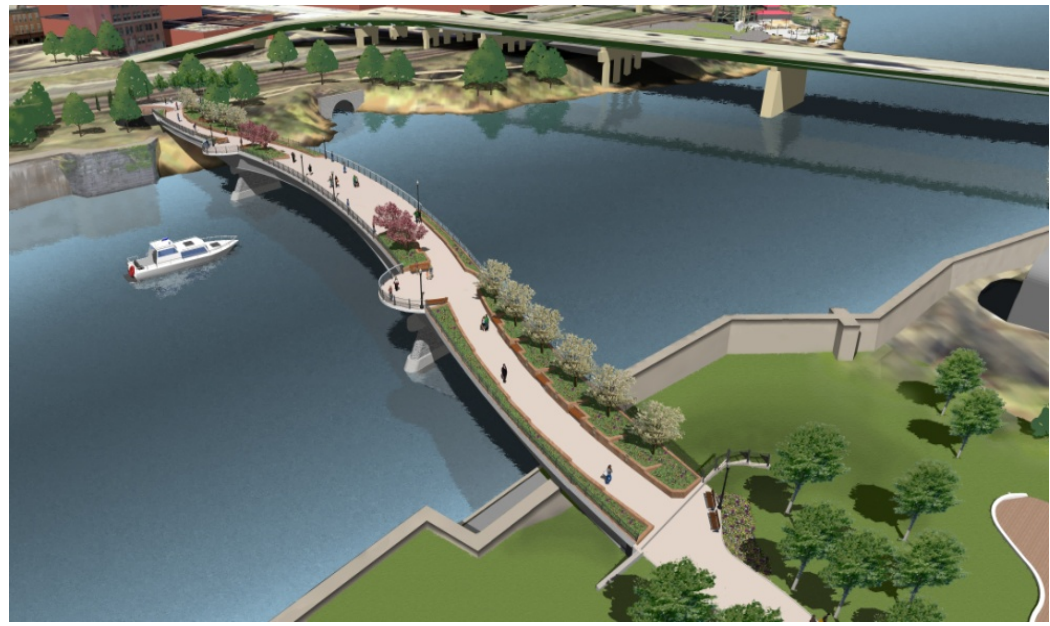

شكل 3. نموذج لممر مشاهدة على أحد الأنهار في نيويورك North shore waterfront.

http://www.governor.ny.gov/sites/governor.ny.gov/files/archive/governor_files/images/TripleCurvePerspective.jpg. visited online on the web on 1Feb. 2016 at 7:35 p.m.

- الإطلالات ويتم اختيار مواقعها في الأماكن

التي يحرص الزوار على مشاهدتها

- أماكن الجلوس في المواقع المخصصة لها،

ويتم تصميمها بعناية.

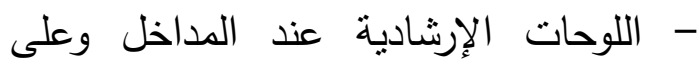

$$
\text { الأطراف للتوجيه والمساعدة. }
$$

- شاشات المعلومات عند المواقع المهمة، وخصوصاً في أماكن الإطلالات.
3-1 العناصر المكونة لمدرات المشاهدة

يعتمد توفر العناصر المكونة لمر المشاهدة

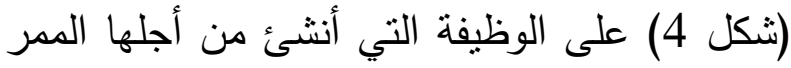

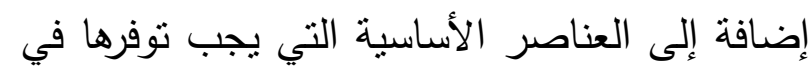

ممرات المشاة [6] والتي عادة ما تتكون من:

- الممر: وهو العنصر الأساس، ويمنل

المسار المخصص لحركة الزوار • 
مربع. ويقع شرق بقيع الغرقد حُشُ كوكب حيث دفن

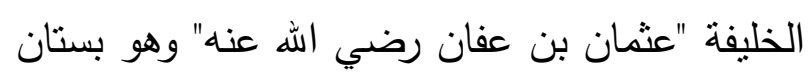
بظاهر الدينة خارج البقيع، وقد كان البقان بلعيع الكبير

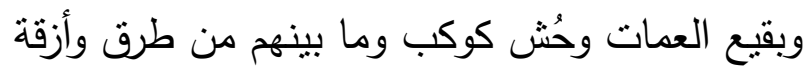
لا تتجاوز مساحتها مجتمعة 150 منراً طولاً وعرضاً

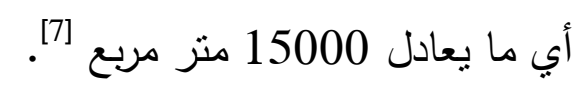

وفي عهد الملك فيصل بن عبد العزيز آل

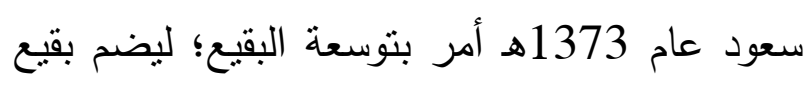

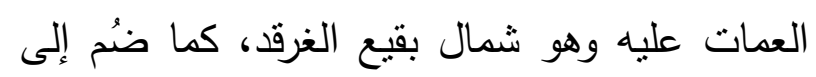

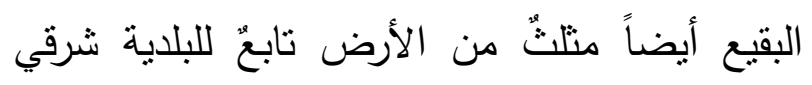
بقيع العمات لتصبح الزيادة في المساحة 5929 متراً

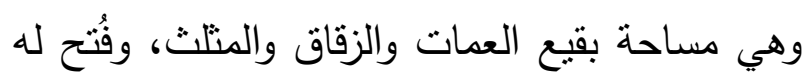
بابان آخران من الجهة الثمالية إضافة للبابين

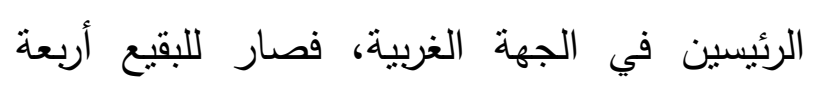

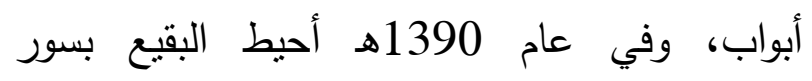

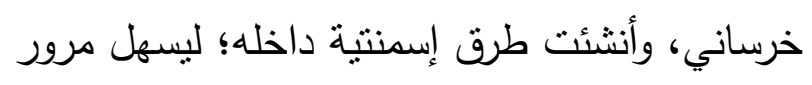

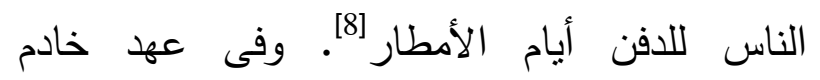

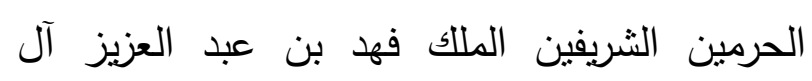
سعود قامت توسعة كبيرة للبقيع وشملت التوسعة التبن

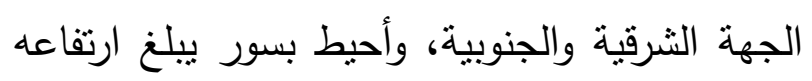
أربعة أمتار وطوله 1700 متر، وأنثئت بوابة كبيرة

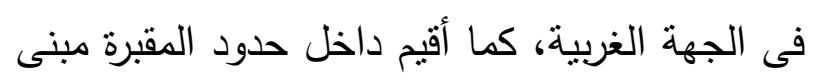
خاص لتحضير الجنائز وإنهاء إجراءاتها. وقد بلغت التهل

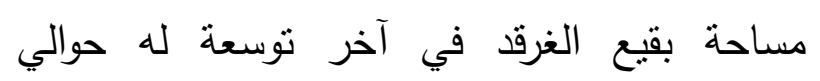

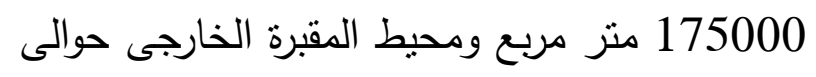

$$
\begin{aligned}
& \text { - التتجير (أحواض الزرع) ويتم اختيار } \\
& \text { نوعية الأتشار التي تتناسب مع المكان. } \\
& \text { - مشارب المياه لتوفير المياه للزوار. }
\end{aligned}
$$

- المظلات لحماية الزوار من أشعة الثمس لهن خصوصاً في البلاد الحارة.

- الحواجز لحماية الزوار من السقوط، وتتتاسب مع المواد التي أنثئ بها الممر .

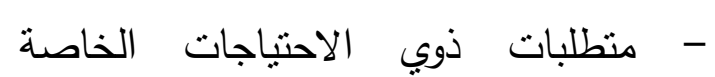
وخصوصاً المنحدرات والدربزينات.

\section{4- الوضع الراهن لمقبرة البقيع}

حيث أن الدراسة تهثم بتهيئة وتحسين زيارة

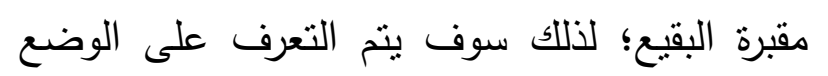

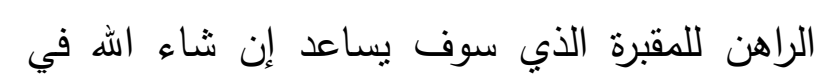

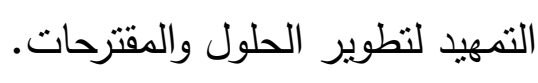

\section{4-1 الموقع والمساحة والخصائص الهنسية}

تقع مقبرة البقيع في الجهة الثرقية للمسجد

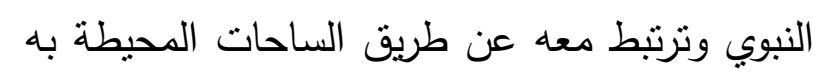
(نكل 5). حيث كان عبارة عن فضاء لاء ينجاوز

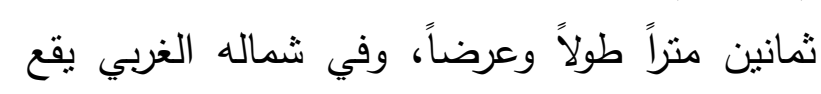

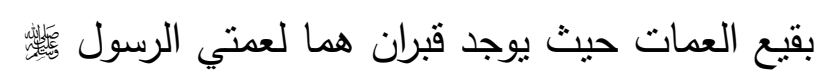

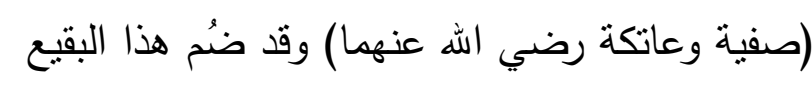

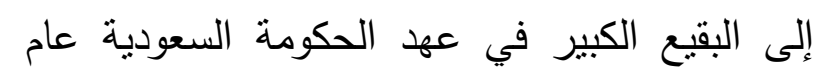
1373هـ، وكذلك ضُم الزقاق الفاصل بينهما والذبي كان يسمى زقاق العمات ومساحته حوالي 824 منر لنر 
يستخدمان فى الدخول والخروج من المقبرة. أما من الجهة الثرقية فلا توجد مداخل أو مخارج للمقبرة

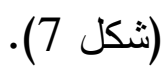

1700 متر طولى [9]. ويوضح شكل 6 الأبعاد الخارجية لأضلاع البقيع من جميع الجهات.

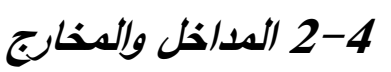

من خلال الدراسة الميدانية تنين أن الممرات

الداخلية بالبقيع لا تنتاسب مع طبيعة النشاط وحجمه، من حيث كونها طويلة ومتعرجة وذات عروض غير كافية فى حدود 2منز تقريباً، وتتقسم الممرات فى المقبرة إلى نمطين مختلفين ففى حين أنها متعرجة فى الجزء الغربى جهة المدخل الرئيس للمقبرة، فإنها تتخذ النمط المنتظم فى الجزء الثرقى من المقبرة، وهو النمط الأكثر مناسبة وتتظبماً

لطبيعة النشاط، (شكل 8).
لمقبرة البقيع مدخل رئيس واحد من الجهة

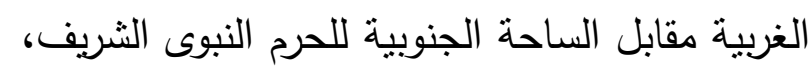
حيث تخرج الجنائز من الحرم بعد الصلاة عليها متوجهة مباشرة إلى البقيع للدفن، ويستخدم هذا لـان

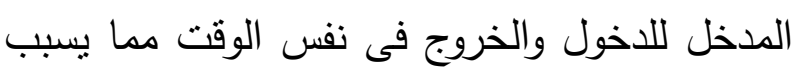
تضاد الحركة وحدوث الازدحام. إضافة للبوابة

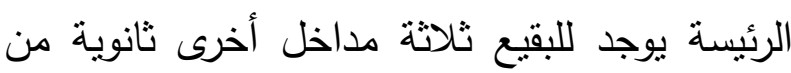

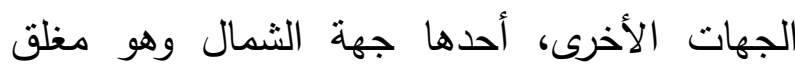

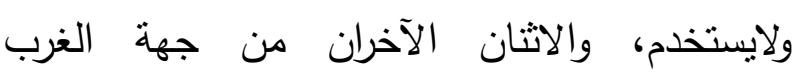
والجنوب ويؤديان إلى مبنى تجهيز الجنائز، ولان الانهان

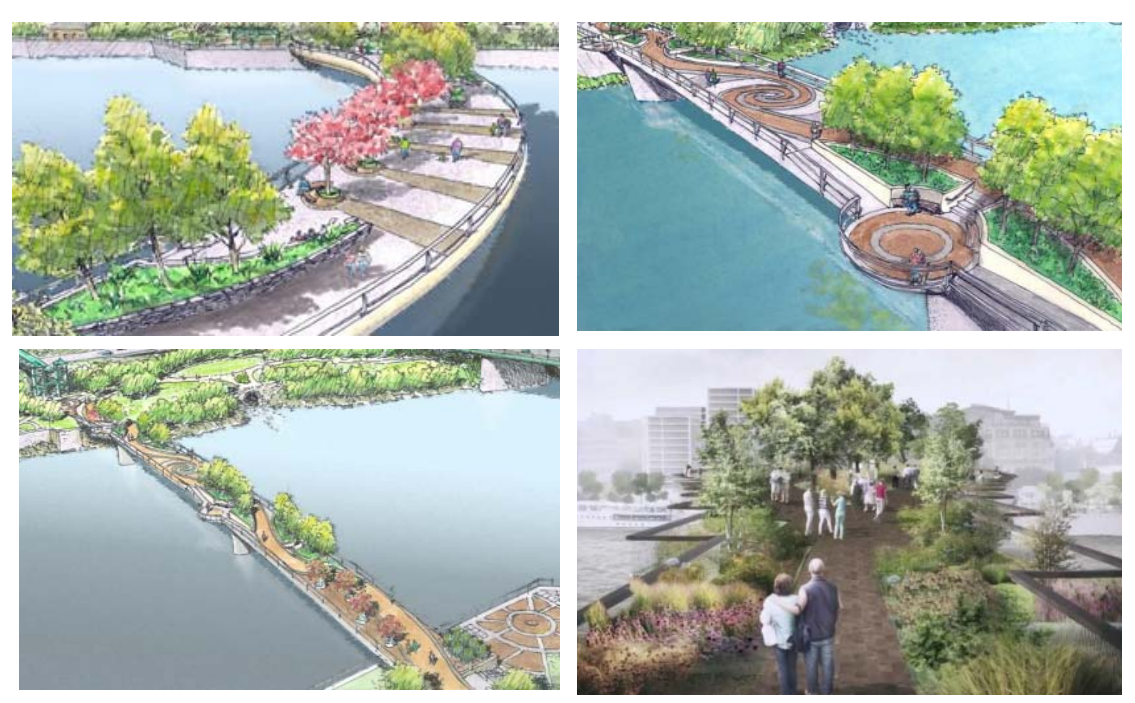

شكل 4: رسم تخيلي للعناصر المكونة لممر المشاهدة في أماكن مختلفة. www.saratogaassociates.com/amsterdam-pedestrian-bridge, 
visited online on the web on 1 Feb. 2016 at 7:35 p.m.
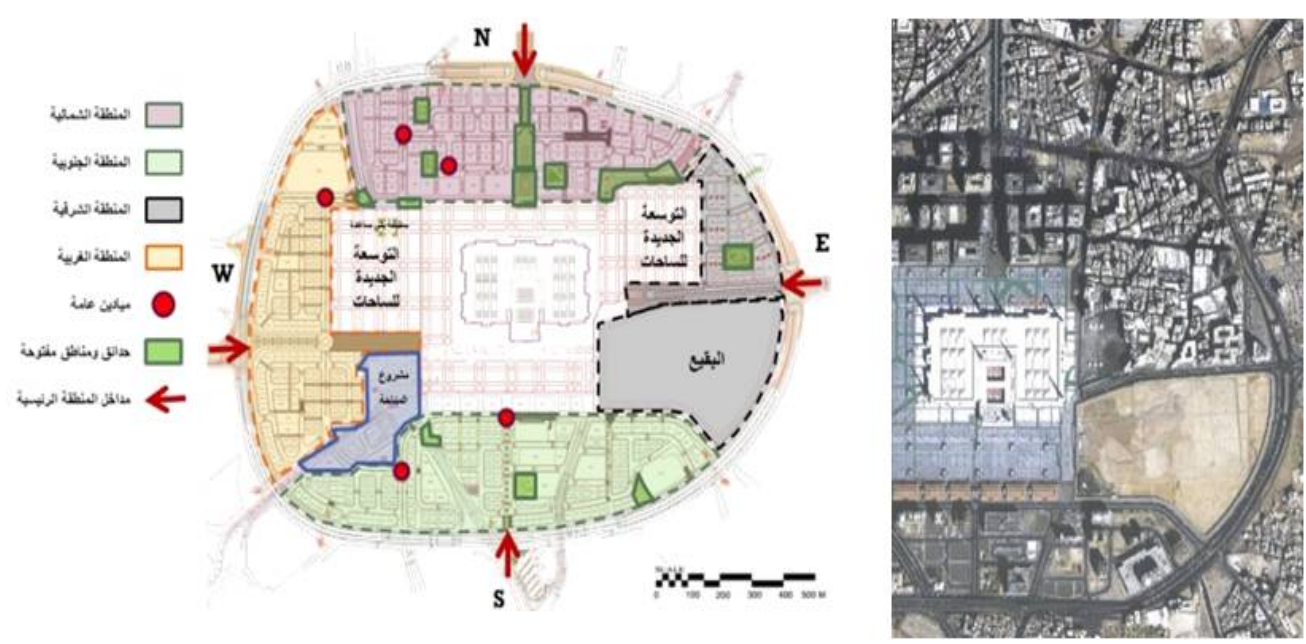

شكل 5: الوضع الراهن للبقيع والمنطقة المركزية المحيطة به (هيئة تطوير المدينة المنورة).

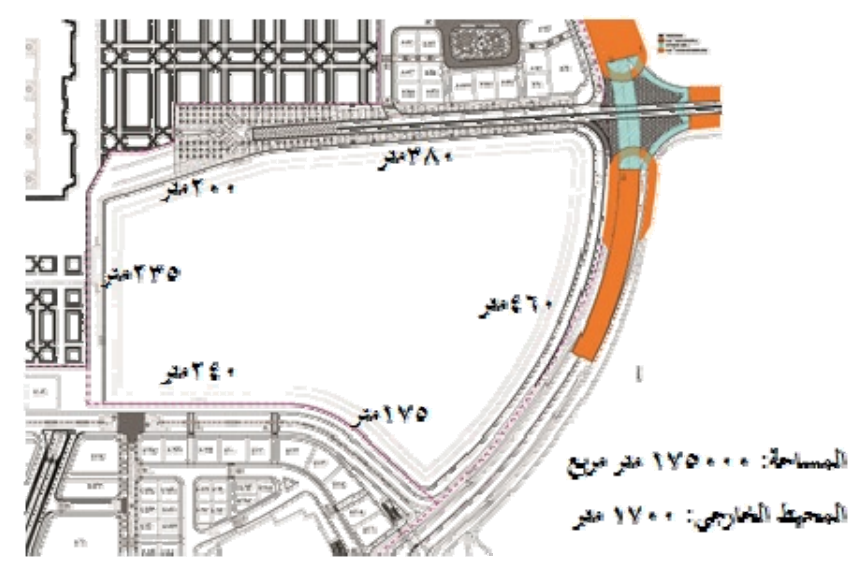

شكل 6: الوضع الراهن لمقبرة البقيع: الأبعاد، المساحة والمحيط الذارجى. المصدر : هيئة تطوير المدينة المنورة.

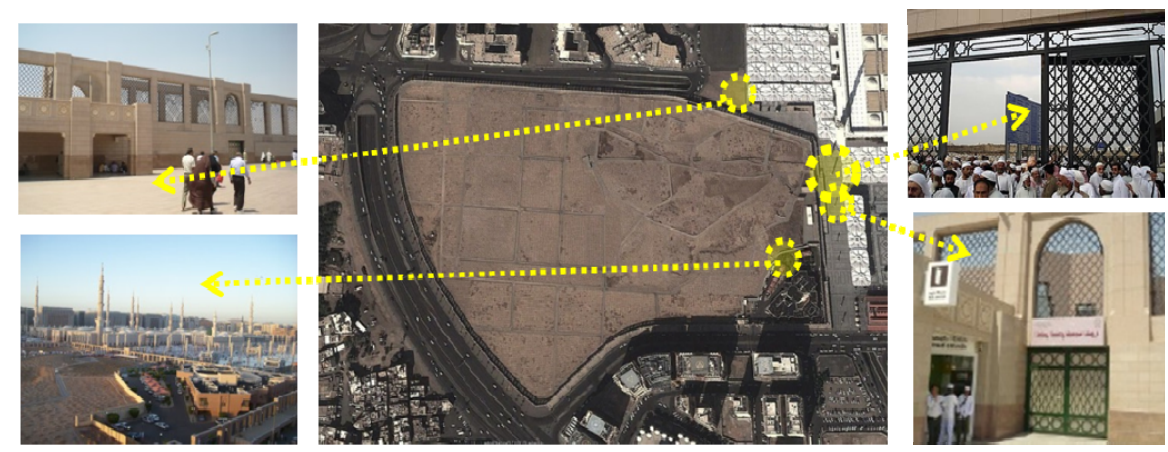

شكل 7: مداخل ومخارج مقبرة البقيع (الباحث). 


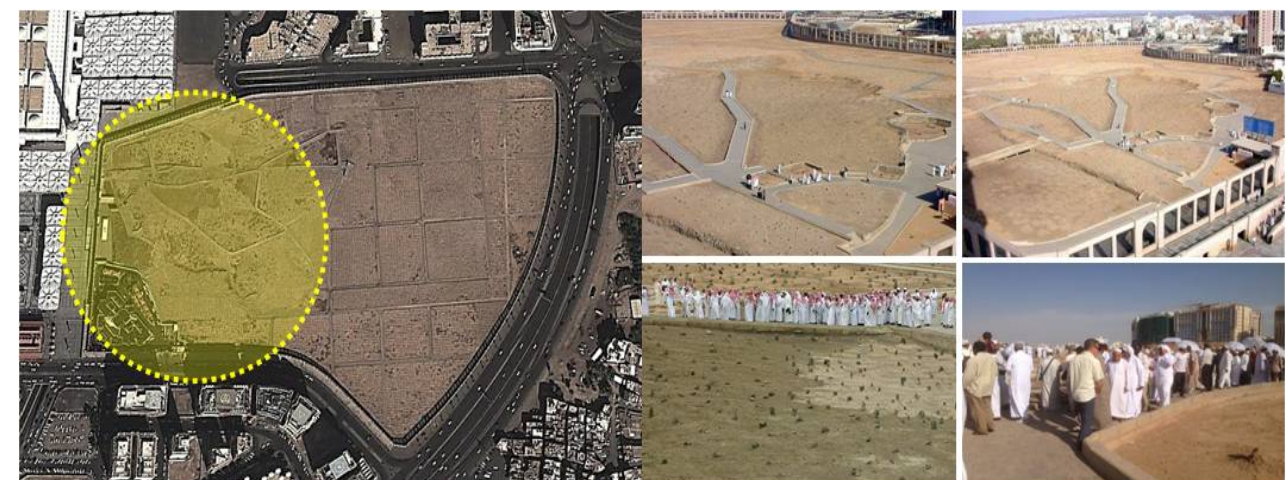

شكل 8: الوضع الراهن للطرق والممرات بمقبرة البقيع بالمدينة المنورة (الباحث).

2- عدد محدود جداً من المقاعد أسفل

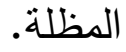

3- عدد محدود من مشارب المياه وأحواض غسيل الأيدي.

4-مجموعة من المظلات البدوية والمعلقة أسفل

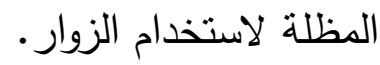

5- عربات كهربائية مخصصة لذوى الاحتياجات

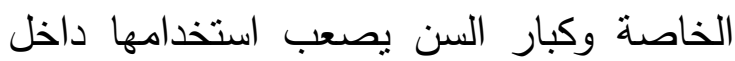

المقبرة لظروف الممرات التي سبق ذكرها.

4-5 الزحام في مقبرة البقيع

تشهد المقبرة وخاصة فى المواسم والأعياد

زحاماً شديداً (الثكل 10) لكثرة الأعداد الراغبة فى لى لئرة

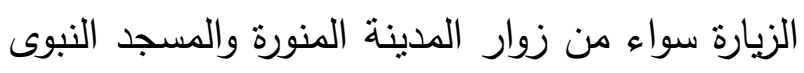
الثريف أو من الأهالى، وفى داخل المقبرة يشت الثناء

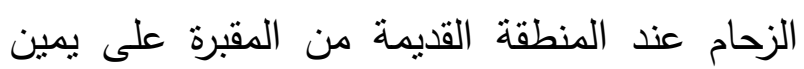
المدخل الرئيس لها، وحول قبور زوجات الرسول

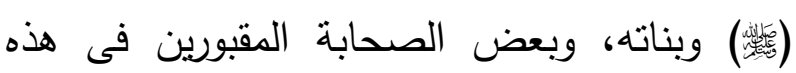

ومن يشارك في تثبيع أي جثمان في بقيع

الغرقد يلاحظ وجود مشقة؛ وذلك لطول المسافة من موضع الصلاة على الجنازة بالمسجد النبوي الثريف إلى بقيع الغرقد، حيث تزيد المسافة عن (300) متر، ثم بعد ذلك طول المسافة مرة أخرى داخل البقيع إلى القبر المعد لدفن الميت تبعاً للمساحة الثاسعة والممرات المتعرجة الطويلة، خصوصاً إذا كان القبر قريباً من الجدار الثرقي؛ مما يدعو إلى ولى ضرورة البحث عن حلول جذرية تسهم في التسهيل والتيسير على الناس.

\section{4-4 الخدمات ببقبرة البقيع}

تتركز الخدمات الموجودة فى المقبرة عند البوابة

الرئيسة فقط (شكل 9)، وهى غير كافية وغير

مناسبة وينقصها التجهيزات اللازمة لذوى الاحتياجات الخاصة وكبار السن. ويمكن حصرها فيما يلي:

1- مظلة صغيرة محدودة المساحة فى

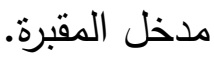




$$
\text { 5- 5 آراء الزوار }
$$

للتعرف على آراء الزوار وحجم الطلب على

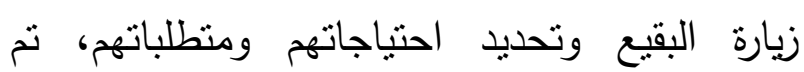
تصميم استبانة تضمنت أربعة أقسام شملت ومانت الخصائص الديموغرافية، ومعلومات أولية، وقياس مدى معرفة الزائرين بتاريخ البقيع ومدى رضاهم عن أوقات الزيارة ومدتها، ومدى توفر الخدمات المختلفة

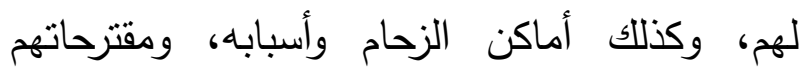

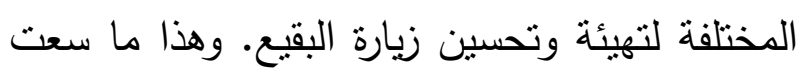

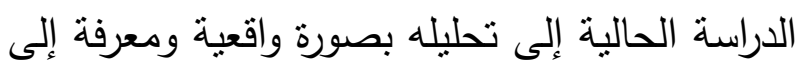
أى حد كانت الزيارة بوضعها الحالي ميسرة ومنظمة، وهذا ما تم طرحه فى أسئلة استبانة البحث، وما كثفت البيانات الإحصائية عنه.
المنطقة، خاصة وأن قصور المعلومات واللوحات الإرشادية والتى توضح وتعرِف بتاريخ البقيع وأهله،

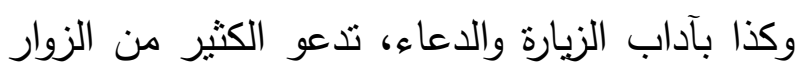
إلى التزاحم حول أعضاء الهيئة المكلفين بتتظيم الزيارة، فى محاولة للحصول على بعض الإجابات والمعلومات التى يبحثون عنها. ويوضح الثكل 11 بعض مظاهر الزحام عند دخول الجنائز واتباعها من العديد ممن برغبون بزيارة

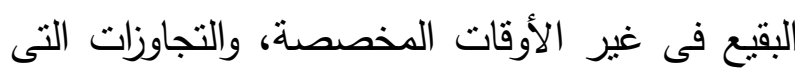
تحدث نتيجة لذلك من دخول لمنبعى الجنازة لمناطق لاوفات

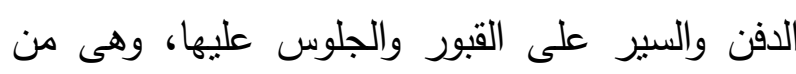

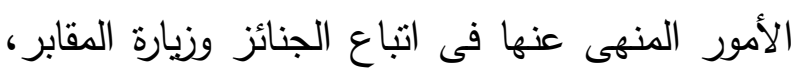

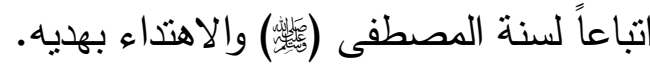

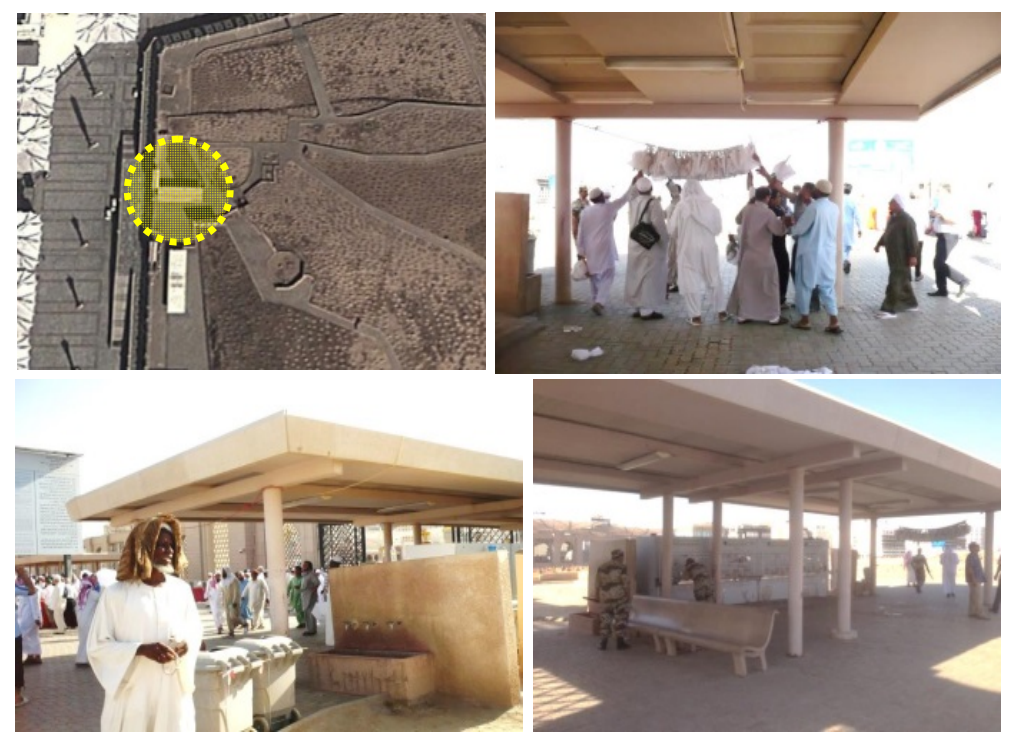

شكل 9. الوضع الراهن للخدمات المتوافرة وأماكن تواجدها (الباحث). 


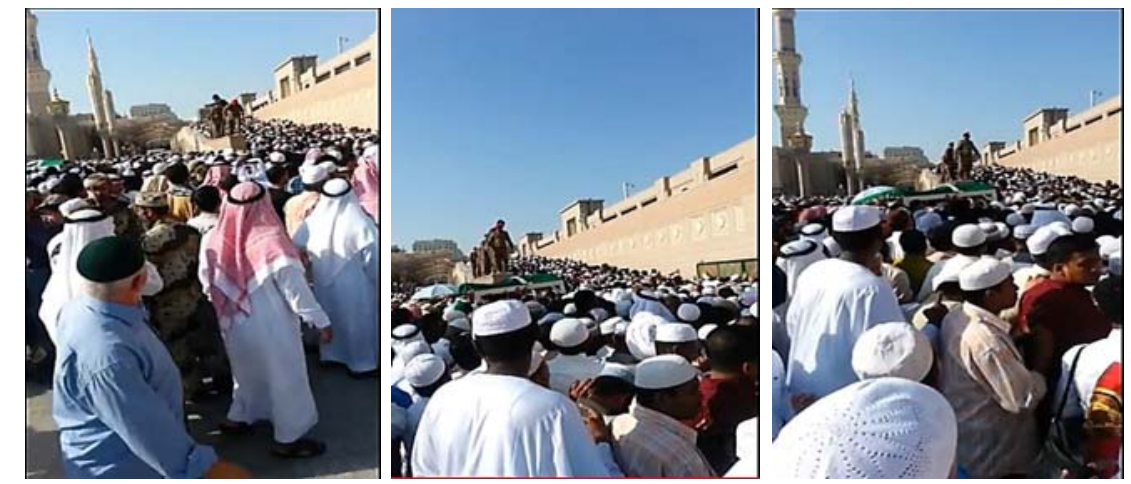

شكل 10. التزاحم عند البوابة الرئيسة للبقيع صبيحة يوم عيد الفطر 1434هـ (الباحث).
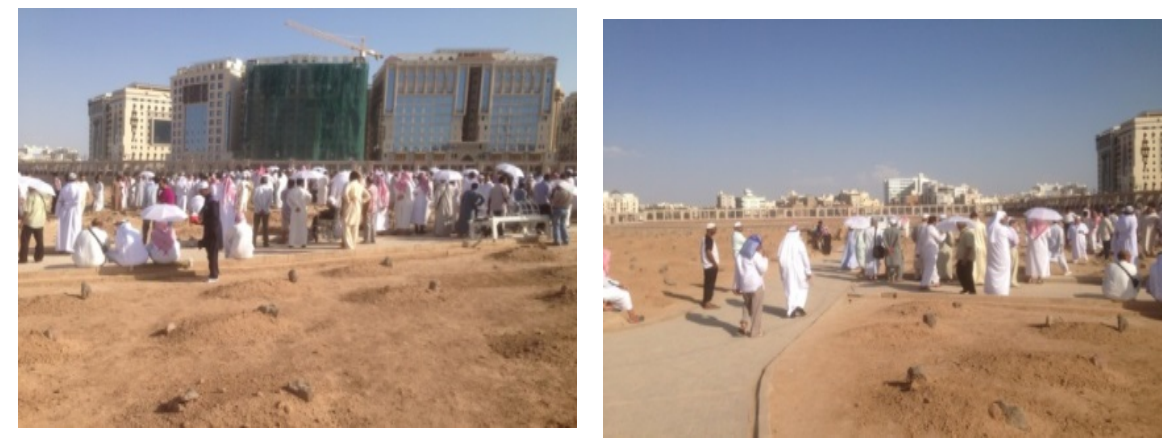

شكل 11. الزحام عند دخول الجنائز والتجاوزات نتيجة للزحام (الباحث).

العينة وفقاً لتلك المستويات. ويتضح من الثنكل أن 1-5 أفراد العينة تتمتع بصفة عامة بمستوى تعليمي بيَّن التحليل الإحصائي أن نسبة كبيرة من

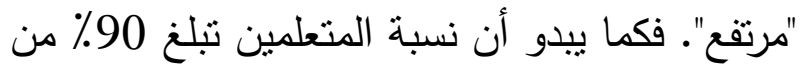
الزوار (57\%) نمتل الجنسيات: الباكستانية بنسبة

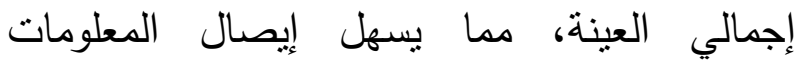

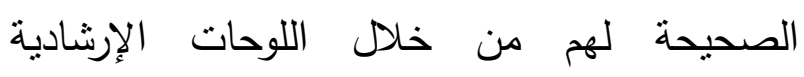
والثاشات الإككترونية بمعظم اللغات. 3-5 مكان الإقامة الدائم

بيَّن التحليل الإحصائي أن غالبية الزوار (60\%) من خارج المملكة (شكل رقم 14)، ويأتي

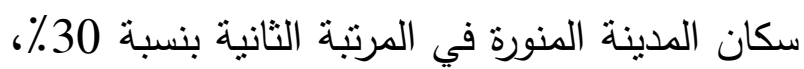
وباقي مدن المملكة نحو 5\% مما يؤكد على ضرورة

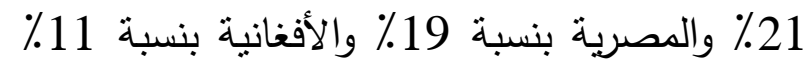
والهندية بنسبة 7٪ فيما توزعت النسبة المتبقية على لونى الجنسيات الأخرى وبنسب صغيرة متفاوتة (ثنكل 12)، حيث يساعد ذلك في اختبار اللغات المناسبة للتوعية والإرشاد كذلك الحال بالنسبة للمرشدين. 5-5 المستوى التعلييسي تشمل استبانة الدراسة ستة مستويات تعليمية متررجة، يوضح الثكل رقم (13) توزيع نسب أفراد 
الجنائز أو لأسباب أخرى (ثكل 17) مما يؤكد أهمية تسهيل الزيارة وتهيئة المقبرة لذلك.

5-7 حجم الطلب على زيارة البقيع

أظهر التحليل الإحصائي أن غالبية زوار المدينة المنورة (78 ٪) يحرص على زيارة البقيع مما يؤكد على ارتفاع حجم الطلب مقارنة بالوقت المتاح للزيارة، ويعزز أهمية تسهيل الزيارة وزيادة وقتها، وإيجاد حلول تساعد على ذللك، كما يمكن أن يكون السبب في عدم رغبة النسبة الأخرى في الزيارة عدم مناسبة مواعيد الزيارة والزحام الثديد في الأوقات المتاحة (شكل 18).

\section{8-5 مدى سهولة ويسر نيارة البقبيع}

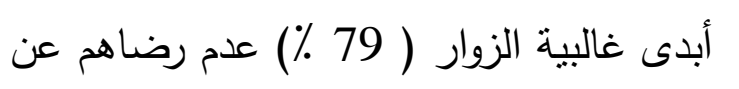

سهولة ويسر الزيارة لمقبرة البقيع؛ مما يدل على أن الن البوال

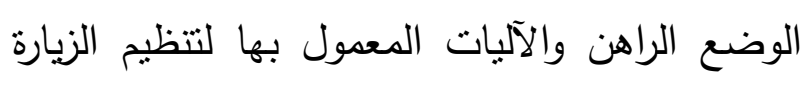
غير مناسبة، حيث يجد معظم الزوار صعوبة في لهاري ذللك قد تصل في بعض الأحيان إلى عدم الرغبة في لزئل الزيارة (شكل 19).

5-9 مدى كفاية ومناسبة الدداخل والمخارج لزيارة البقيع فى الوضع الزاهن

يوضح الثكل 20 توزيع أفراد العينة وفقاً لمدى كفاية ومناسبة المداخل والمخارج فى الوضع الراهن لزيارة البقيع؛ ومنه يتضح أن نسبة عالية من

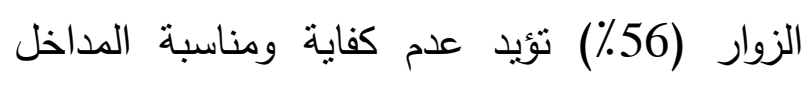

إتاحة الوقت الكافي للزيارة؛ حتى يتمكن القادمون من

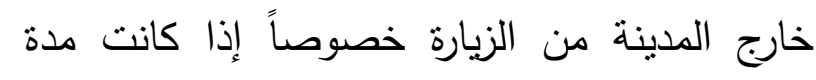
إقامتهم محدودة. 4-5 علد ملات زيارة البقيع يتضح من الثكل (15) أن الغالبية العظمى

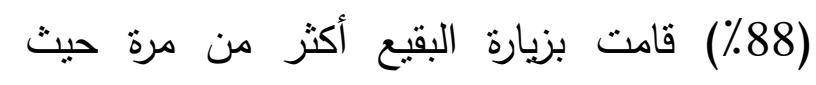

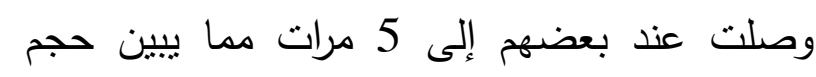
الطلب، في حين بلغت نسبة من لم يقم بزيارة البقيع

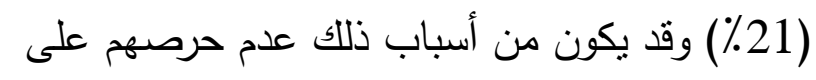

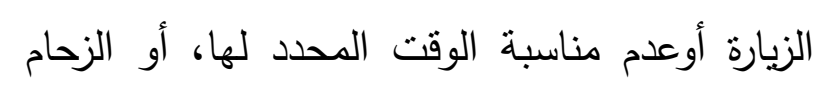
الثديد في أوقات الزيارة. 5-5 5 5ل5 النيارة

يتضح من التحليل الإحصائي أن الغالبية

(76.3\%) يتراوح زمن زيارتهم للبقيع بين 10 دقائق

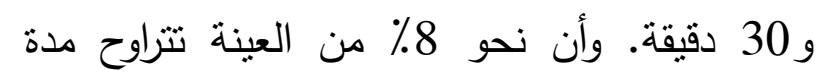

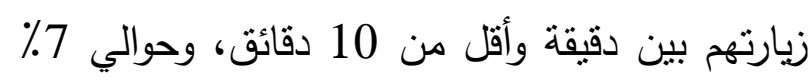
من العينة يتراوح مدة زيارتهم بين نصف دئن ساعة ونة وساعة (شكل 16) ومما سبق يمكن تحديد المدة

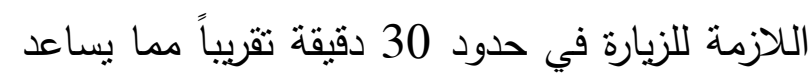
في تحديد الوقت عند تطبيق الجدولة الزمنية. 6-5 أسباب نيارة البقيع بيَّن التحليل الإحصائي أن السبب الرئيس لزيارة للبقيع عند الغالبية العظمى من الزوار (85\%)

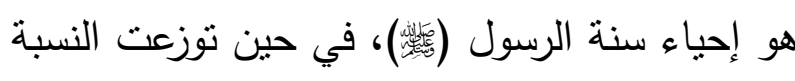

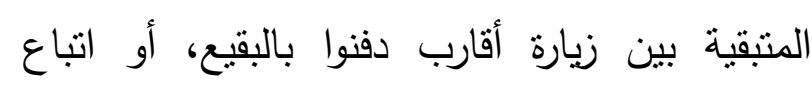


والمخارج لحجم النشاط، وقد يرجع ذلك إلى استخدام للزيارة لمدة قصيرة لا تتجاوز الساعة فى أفضل بوابة واحدة للاخول والخروج، وضيق الوقت الأحوال، ثم يمنع الدخول فى باقى المدة المحددة المخصص للزيارة، حيث يتم فتح الأبواب للاخول للزيارة، ويسمح بالخروج فقط من نفس البوابة.

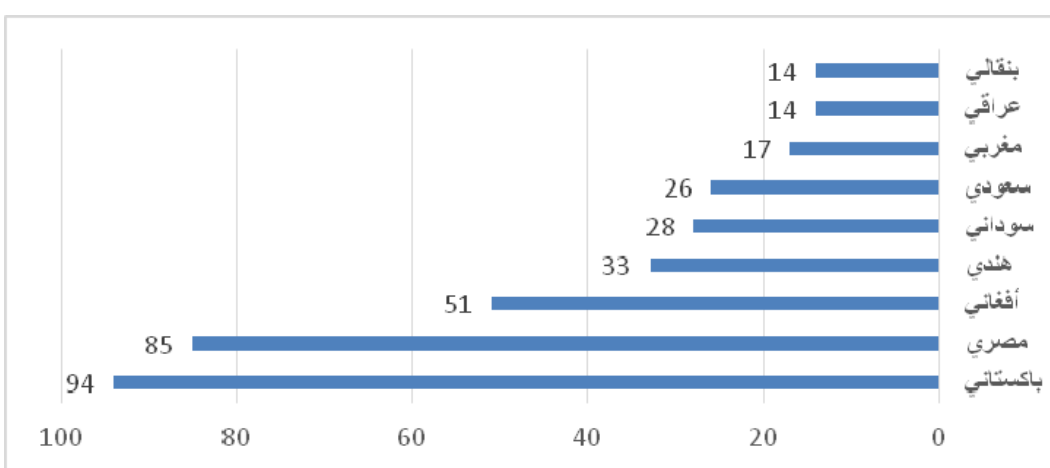

شكل 12. التحليل الإحصائي لجنسيات الزوار.

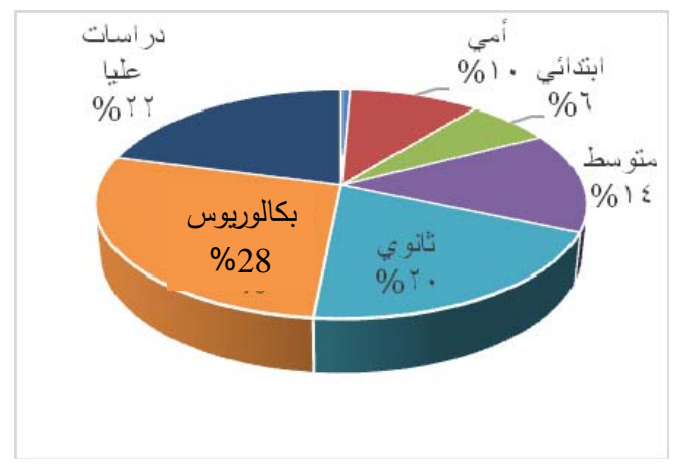

شكل 13. المستوى التعليمي للزوار.

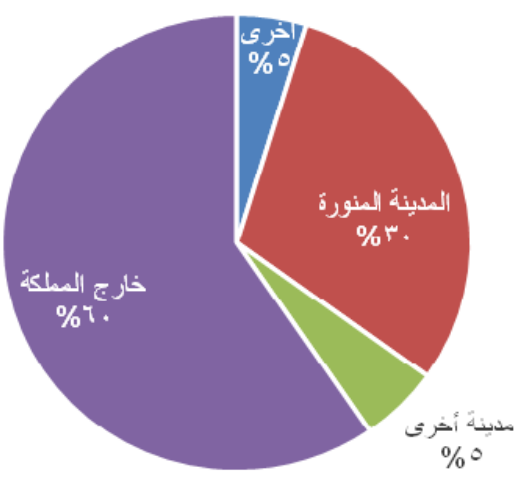

شكل 14. مكان الإقامة الدائم. 


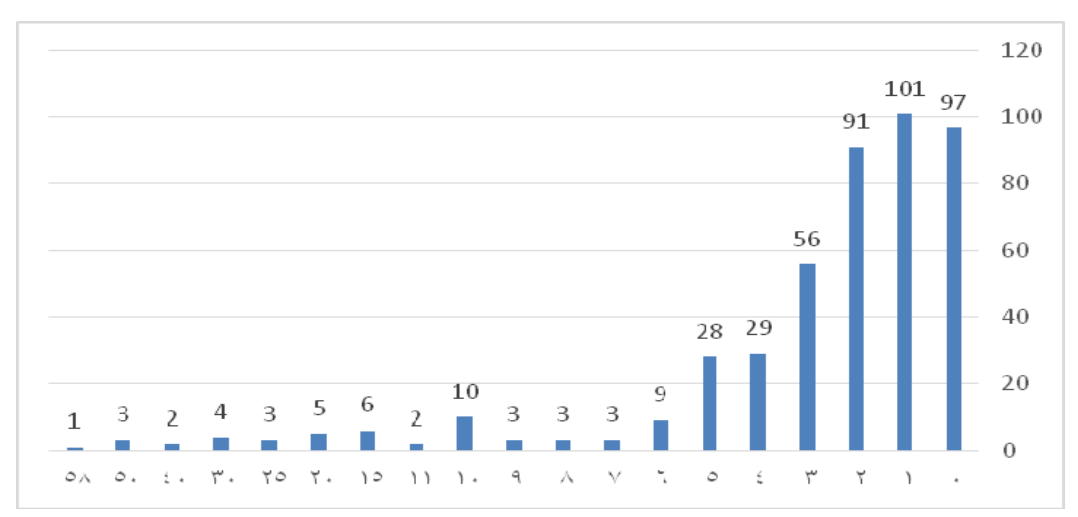

شكل 15. عدد مرات زيارة البقيع.

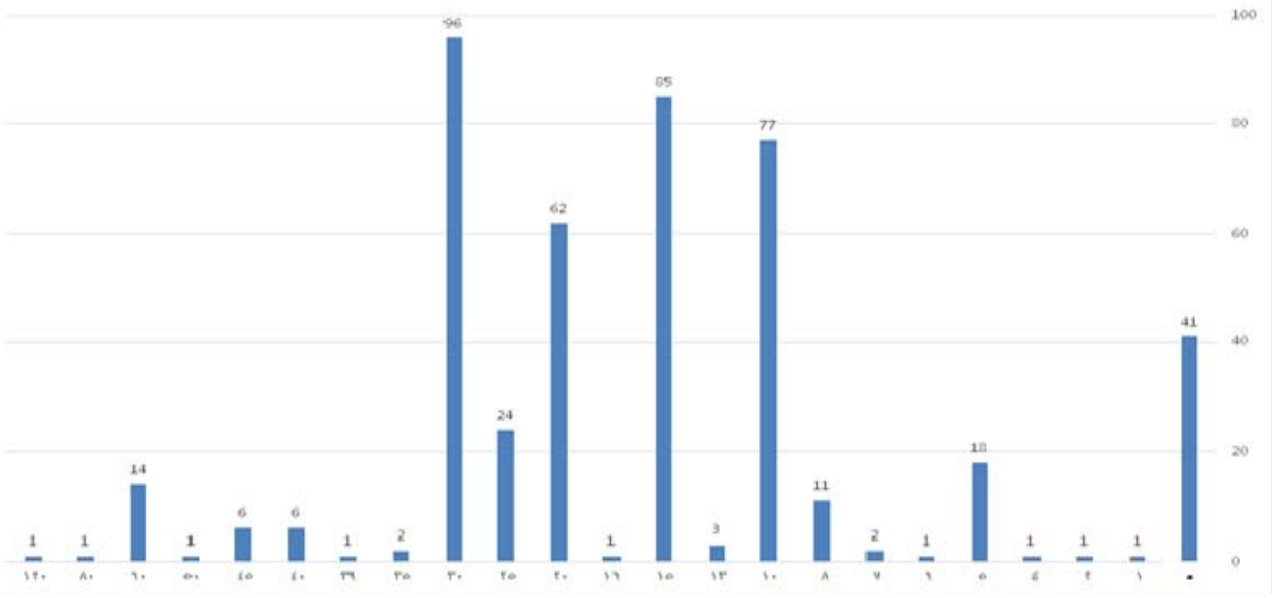

شكل 16. مدة زيارة البقيع بالدقيقة.

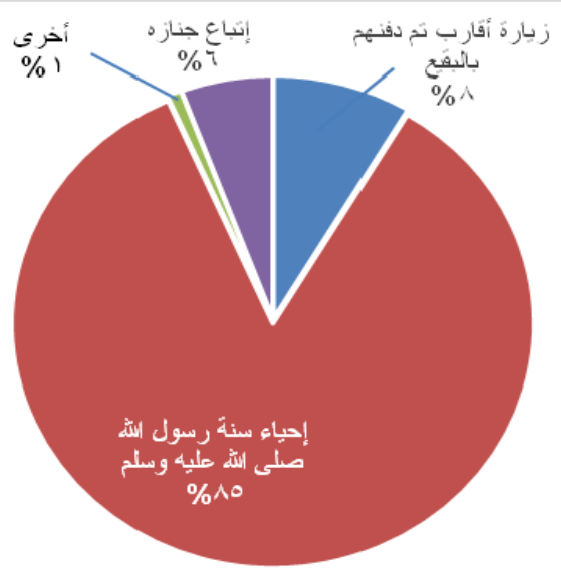

شكل 17. أسباب زيارة البقيع. 


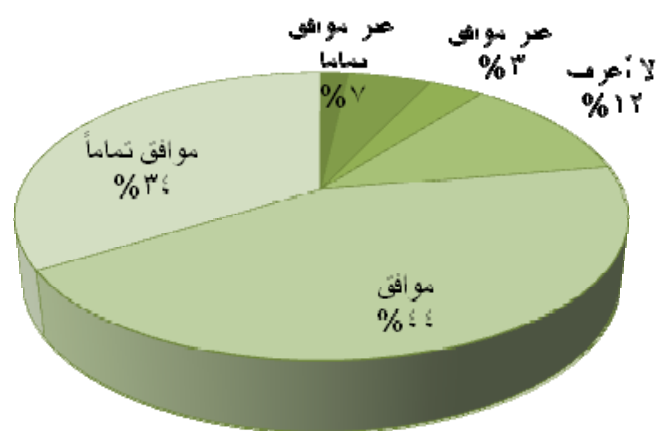

شكل 18. الوضع الراهن للتوعية والإرشاد بمقبرة البقيع بالمدينة المنورة.

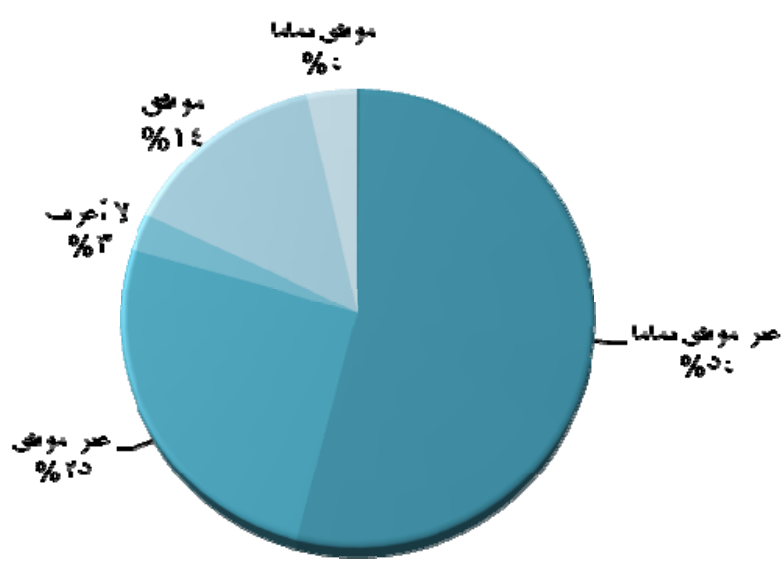

شكل 19. توزيع أفراد العينة وفقا لمدى رضاهم عن سهولة ويسر زيارة البقيع.

11-5 مدى تواجد تجهيزات كافية لكبار السن وذوى الاحتياجات الذاصة لزيارة البقيع لناجيع

ولمعرفة مدى توفر تجهيزات كافية لكبار

السن وذوى الاحتياجات الخاصة لزيارة البقيع، أكد نودئه الغالبية (66\%) عدم تواجد تجهيزات كافية لكبار السن وذوى الاحتياجات الخاصة داخل المقبرة

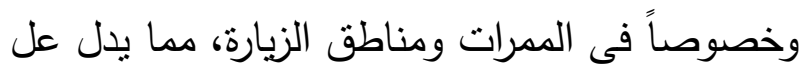

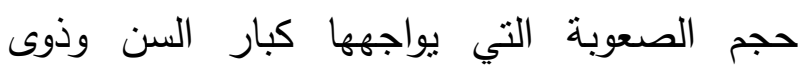
الاحتياجات الخاصة في زيارتهم للبقيع (شكل 22).
5-10 مستوى الزحام فح نيارة البقيع فى الوضع الراهن

وللتعرف على مستوى الزحام داخل المقبرة

وفي الممرات ومواقع الجذب وقت الزيارة، أكد غالبية الزوار (71\%) وجود زحام شديد أثناء وقت الزيارة،

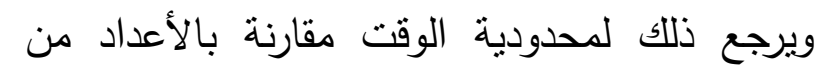

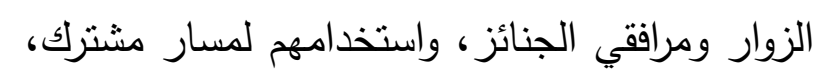
إضافة إلى تجمع الزوار حول أفراد الهيئة لقلة

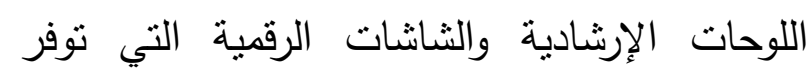

المعلومات (ثكل 21). 
أما بخصوص مناسبة عروض الممرات داخل المقبرة، فتبين أن نسبة كبيرة من الزوار (61\%) تؤيد عدم مناسبة عروض الممرات وضيقها، مما ينسبب في حدوث اختاقات خصوصاً في حالة وجود جنائز وعدد كبير من الزوار وهذا يؤكد ما سبق ذكره "لابد

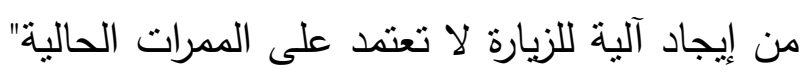

5-15 مناسبة أوقات نيارة البقيع فى الوضع الراهن بخصوص مناسبة أوقات الزيارة في الوضع الراهن بتضح أن حوالى أكثر من نصف العينة

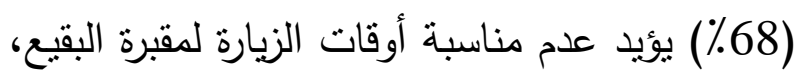
مما يتطلب إيجاد حلول لتمكين الزوار من الزيارة في أي وقت مناسب للزوار ( شكل 26).
أفادت نسبة كبيرة من الزوار (59\% ) بعدم كفاية

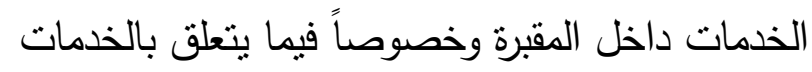

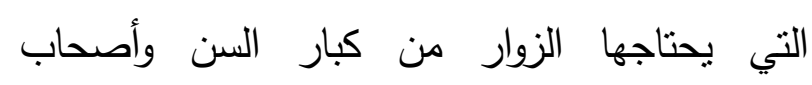
الاحتياجات الخاصة، الأمر الذي بتنطلب توفيرها بالقدر الكافي وفي المكان المناسب (الثكل 23). 13-5 مناسبة المعرات د/خل البقيع

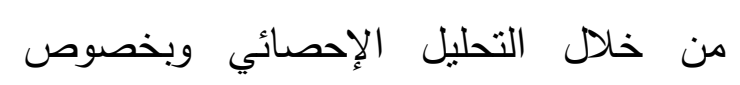
مناسبة الممرات داخل مقبرة البقيع، اتضح أن أكثر من النصف (58\%) تؤكد على عدم مناسبة الممرات

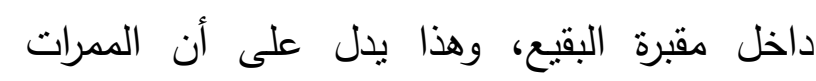

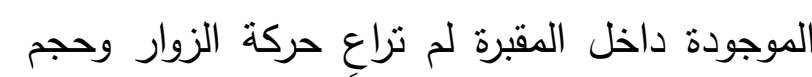
الطلب العالي على الزيارة لذلك لابد من إيجاد آلية

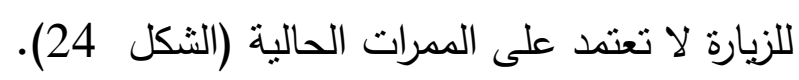

\% w

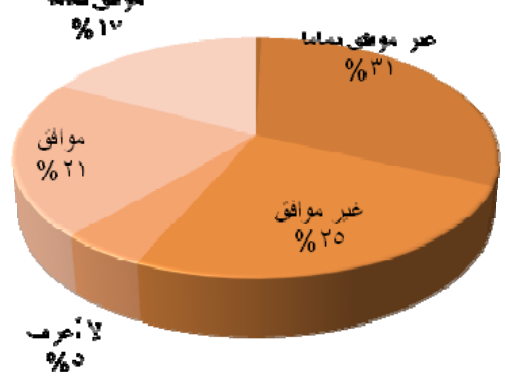

شكل 20. مدى كفاية ومناسبة المداخل والمخارج فى الوضع الراهن لزيارة البقيع.

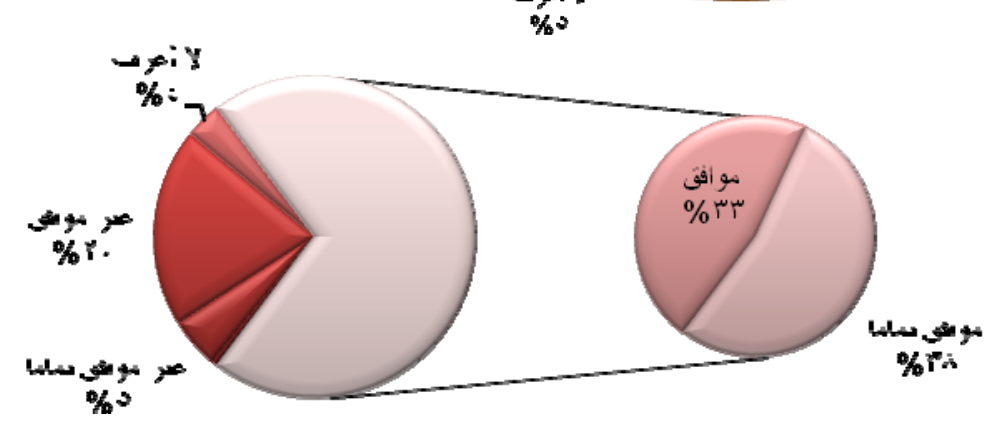

شكل 21. توزيع أفراد العينة وفقاً لددى سهولة ويسر زيارة البقيع. 


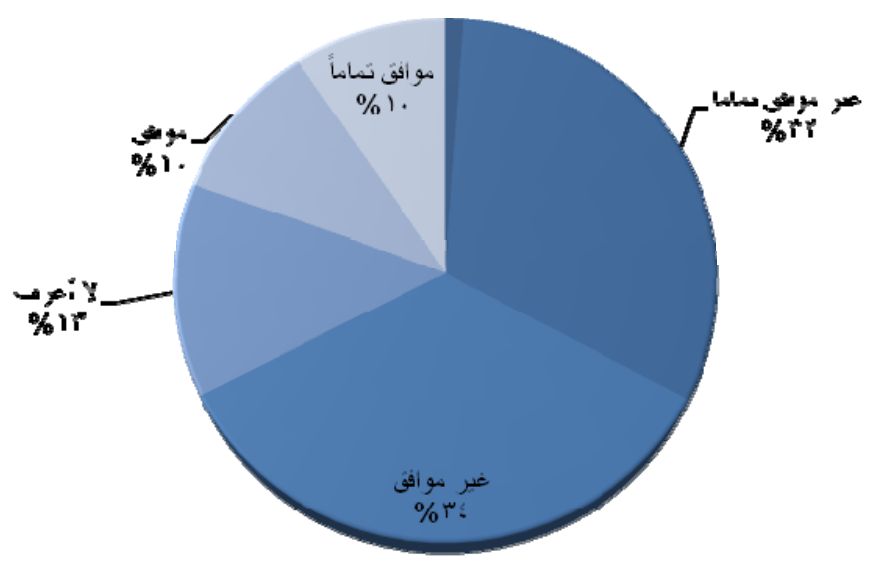

شكل 22. توزيع أفراد العينة وفقاً لمدى تواجد تجهيزات كافية لكبار السن وذوى الاحتياجات الخاصة لزيارة البقيع.

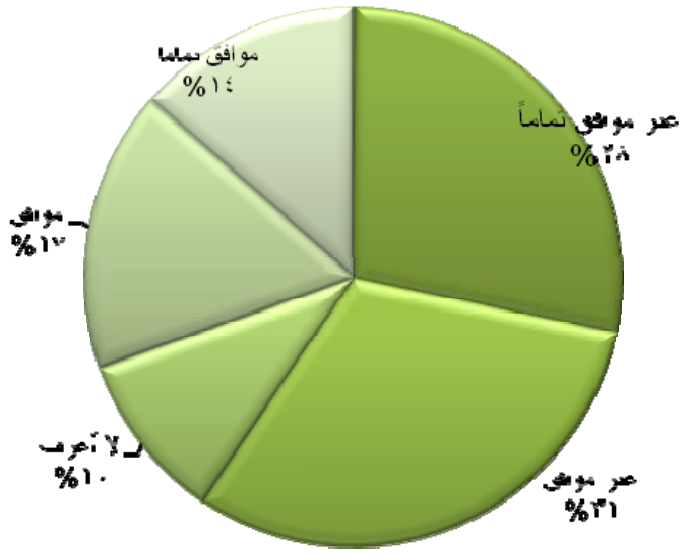

شكل 23. توزيع أفراد العينة وفقاً لمدى تواجد خدمات كافية لزيارة البقيع.

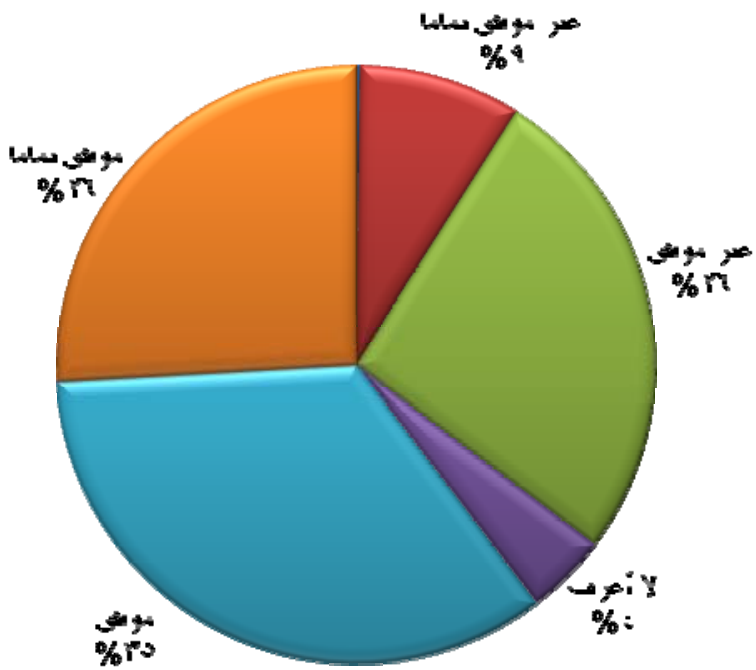

شكل 25. توزيع أفراد العينة وفقاً لضيق عروض ممرات الزيارة داخل البقيع. 


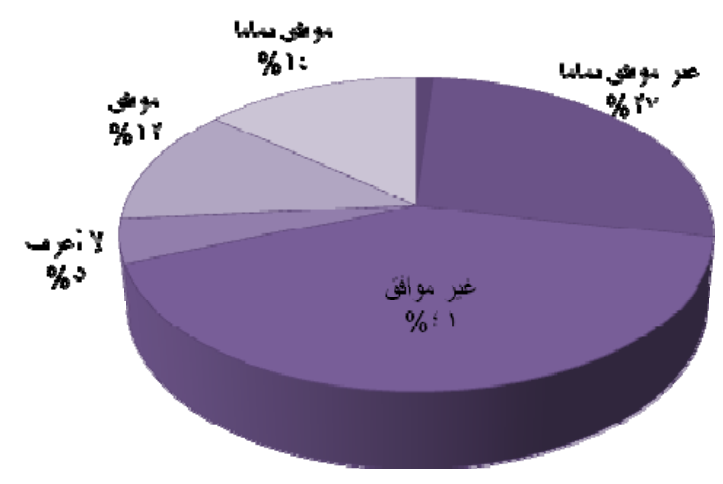

شكل 26. توزيع أفراد العينة وفقاً لمدى مناسبة أوقات الزيارة فى الوضع الراهن.

- تكثيف اللوحات التي تحتوي على المعلومات المهمة. - توفير الخمات الأساسية وخصوصاً مشارب المياه. - توفير منطلبات كبار السن ونوي الاحتياحات الخاصة.

$$
\text { 6- الربط التحليلي بين النتائج }
$$

لتحقيق الربط بين النتائج السابقة تم عمل ربط

تحليلي بين بعض الخصائص الاجتماعية ومستويات الرضى عن بعض العناصر حيث تم اختيار الجنسية

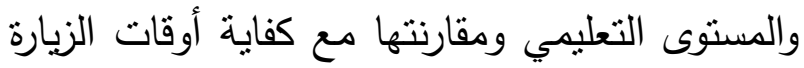
وعدد مرات الزيارة وكانت النتائج على النحو التالي: 6-6 العلاقة بين الجنسية وعلد مرات الزيارة

من خلا مقارنة جنسيات الزوار مع عدد مرات الزيارة (شكل 29) تنين أن غالبية الزوار زاروا البقيع لمرة واحدة، إلا أن بعض الجنسيات تقوم بتكرار الزيارة وخصوصاً الزوار من الجنسيات الأفغانية والمصرية الهان بعضية والباكستانية حيث تجاوزت زيارتهم الخمس مرات، مما لمات يتطلب إيجاد آلية للحد من تكرار الزيارة وتكثيف البرامج التوعوية لتخفيف الزحام وتمكين الآخرين من ليجن

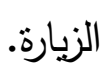

16-5 مدى كفاية أوقات الزيارة

أكد غالبية الزوار (70\%) عدم كفاية المدة المخصصة لأوقات الزيارة لمقبرة البقيع خصوصيًا كما ذكر سابقاً أن إخراج الزوار بستقطع جزءاً من

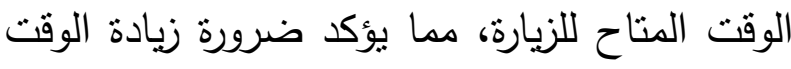
المخصص للزيارة ومراعاة ذلك عند تقديم المقترحات والحول (شكل 27). 5-17 وضع التوعية والإشاد

وفيما يخص التوعية والإرشاد داخل المقبرة، أكد غالبية أفراد الزوار (78\%) عدم وجود لوحات إرشادية لإنات للتعريف بمسار الزيارة داخل مقبرة البقيع (شكل 28) مما ينسبب في توهان الزوار والحاجة لوقت طويل

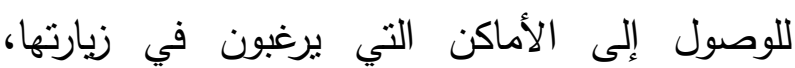
واعتمادهم على سؤال الزوار الآخرين للوصول. 18-5 تركزت معظم مقترحات الزوار في:

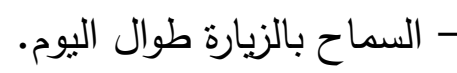
- زيادة الوقت المخصص للزيارة. 


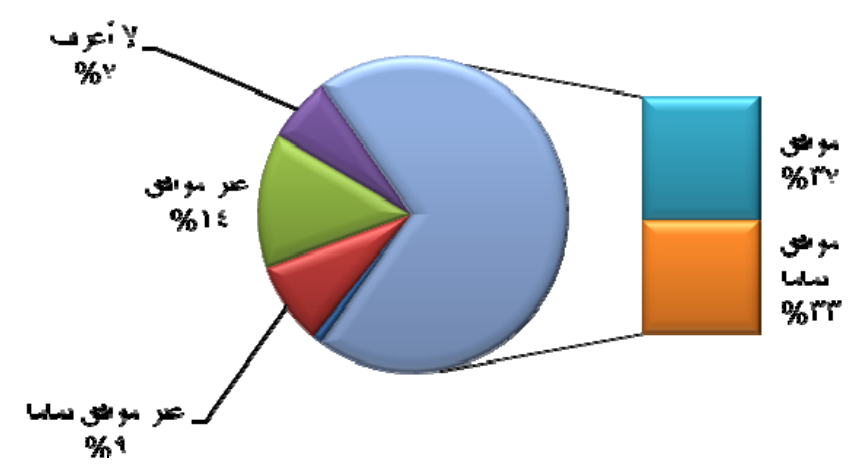

شكل 27. توزيع أفراد العينة وفقاً لمدى كفاية أوقات الزيارة فى الوضع الراهن.

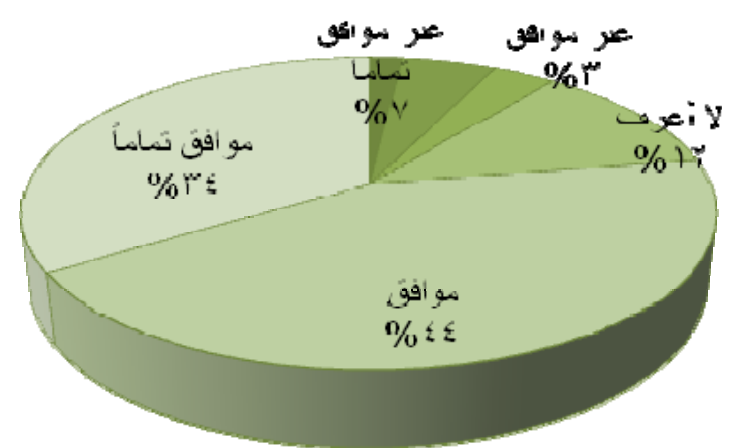

شكل 28. توزيع أفراد العينة وفقا لمدى وجود لوحات إرشادية بمسار الزيارة بمقبرة البقيع.

المستويات العلمية العالية أقل في عدد مرات الزيارة من الزوار الأقل في المستوى العلمي، وهذه نتيجة طبيعية في منل هذه النشاطات. 6-6 العلاقة بين المستوى العلمي وكثابة أوقات الزيارة بمقارنة المستوى العلمي للزوار وكفاية الوقت

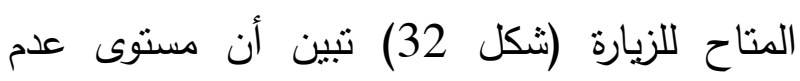

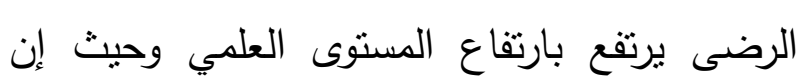
غالبية الزوار من أصحاب المستويات العلمية العالية (90 \% مما يؤكد ضرورة زيادة الوقت المتاح للزيارة

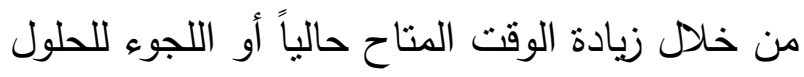

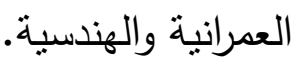

6-2 العلاقة بين الجنسية وكفاية وقت النيارة بمقارنة جنسية الزوار وكفاية الوقت المتاح للزيارة (شكل 30) تبين أن غالبية الزوار بمختلف جنسياتهم غير راضين عن الوقت المناح للزيارة ويظهر عدم الرضى بوضوح في الجنسية الباكستانية

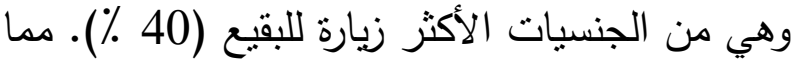
يتطلب زيادة وقت الزيارة أو إيجاد آلية تمكنهم من

$$
\text { الزيارة في أي وقت. }
$$

6-4 العلاقة بين المستوى العلدي وعلد ملات النيارة بمقارنة المستوى العلمي للزوار وعدد مرات الزيارة (شكل 31) تيين أن غالبية الزوار أصحاب 


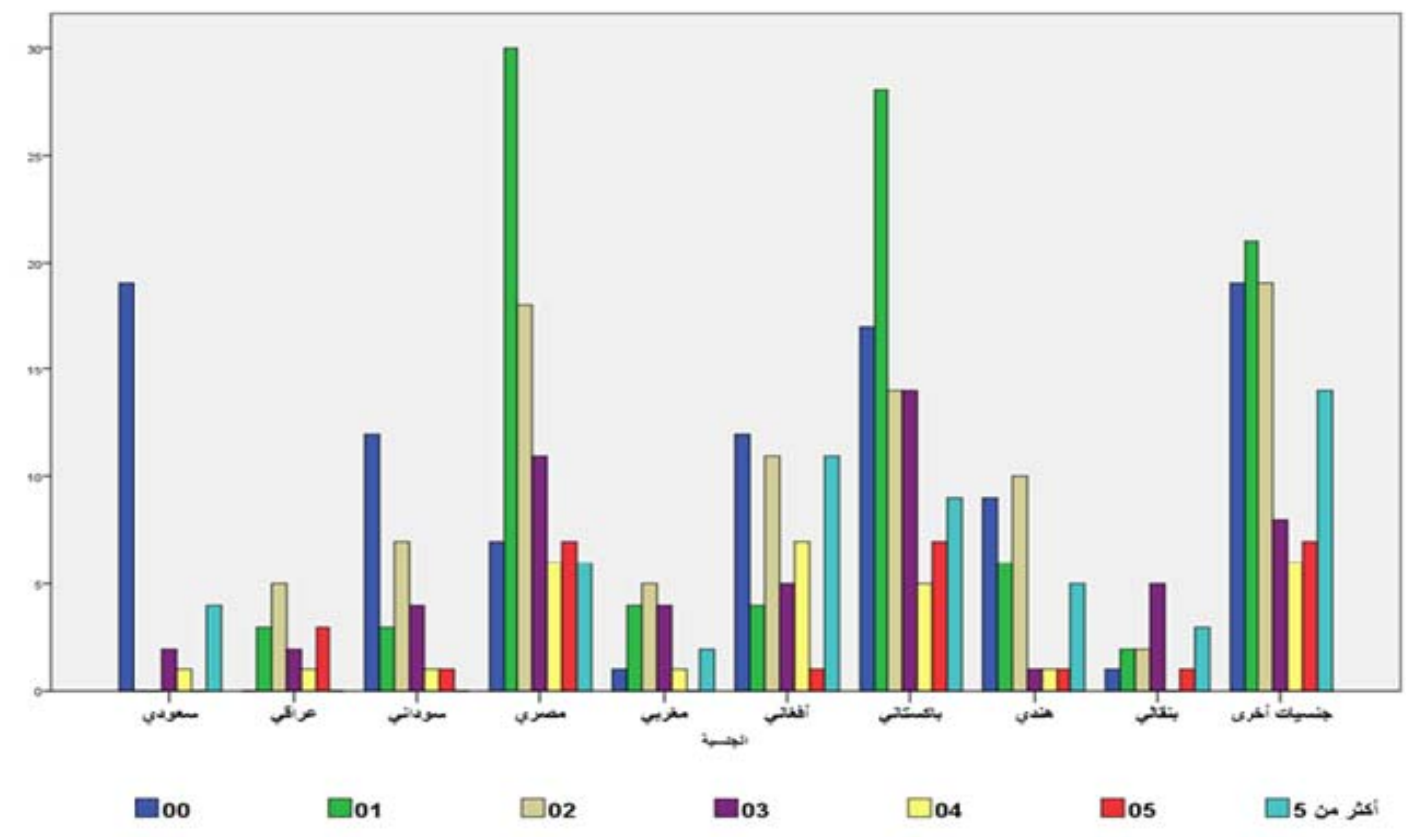

شكل 29. العلاقة بين الجنسية وعدد مرات الزيارة.

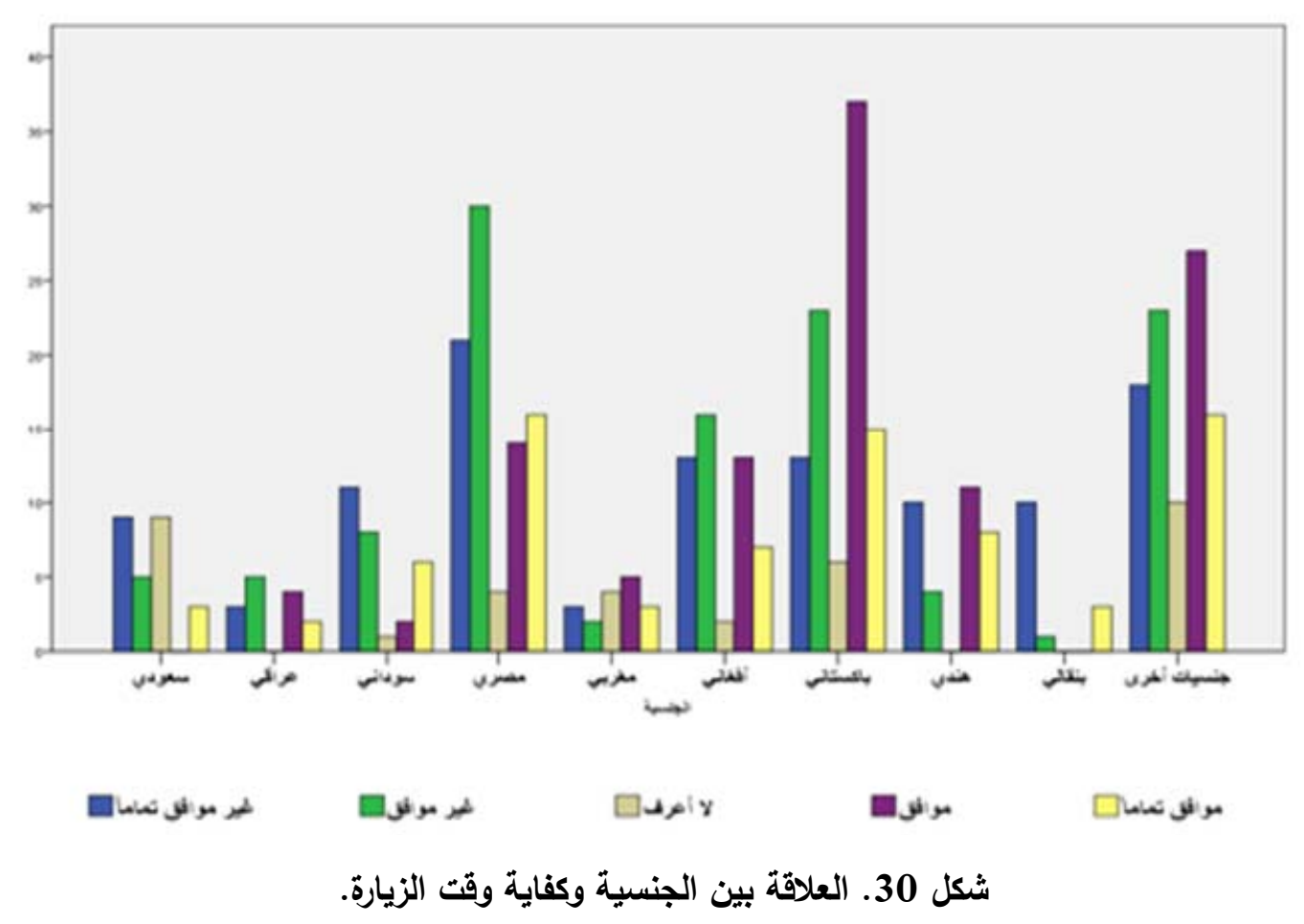



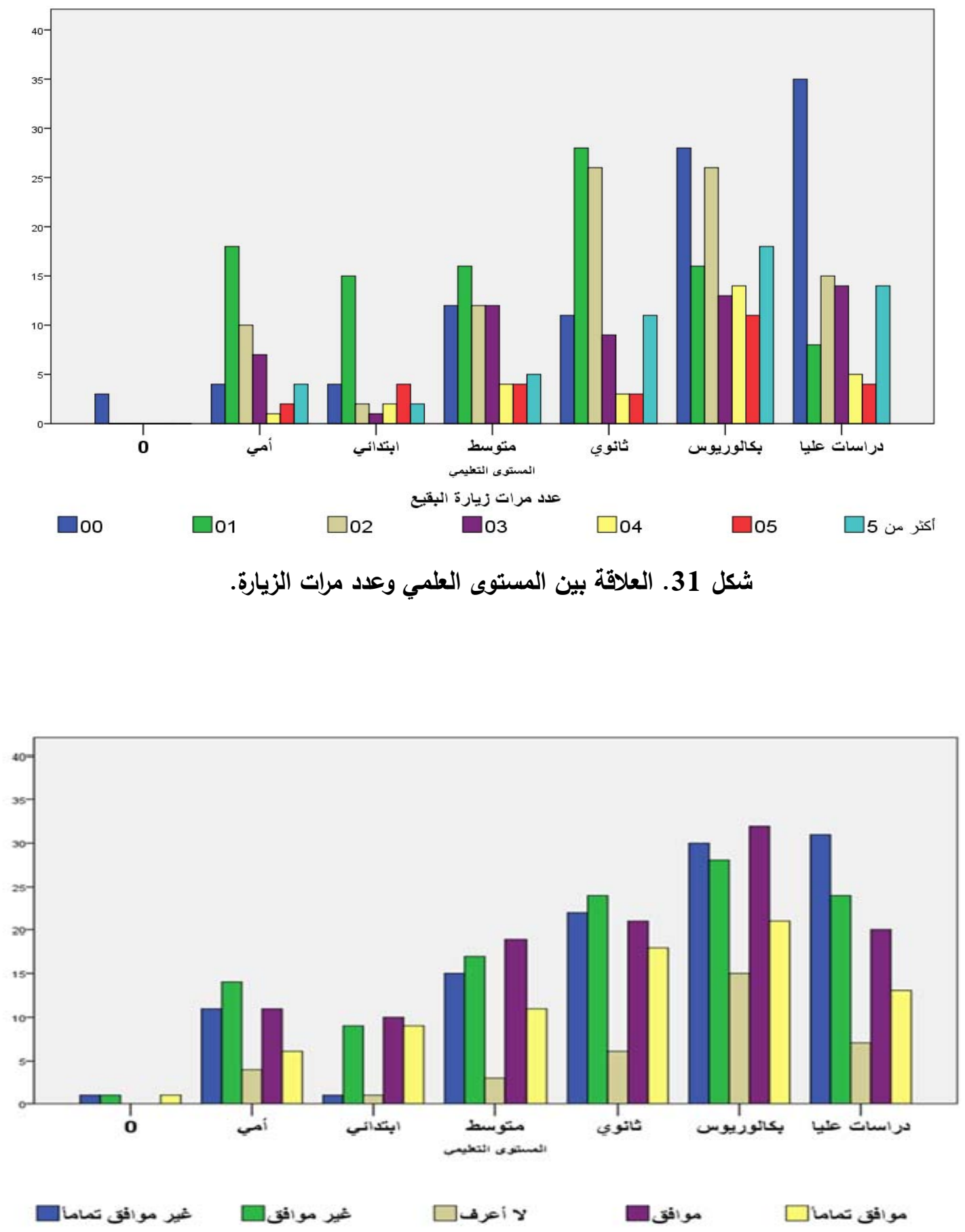

شكل 32. العلاقة بين المستوى العلمي وكفاية أوقات الزيارة. 
4. التصرفات الخاطئة للزوار (كما سبق

الذكر) والتي يعاني منها القائمون على تتظيم الزيارة حيث يصعب مراقبتهم ومنعهم لكبر المساحة وكثرة العدد.

5. قلة القائمين على عملية الإدارة والتتظيم وصعوبة أداء عمله بكفاءة عالية داخل المقبرة وأثناء الزيارة، نتيجة لتواجدهم داخل مساحة كبيرة مع

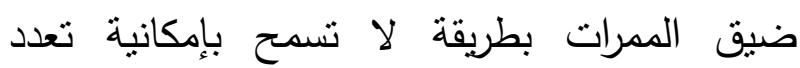
الخطط التتخيلية وعمليات التفويج. 6. الأبعاد الثقافية والاجتماعية للزوار وعدم

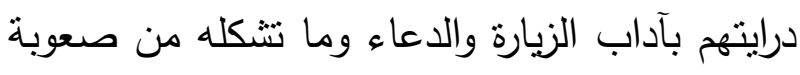
في التعامل معهم. 7. التأثير السلبي لانعدام الخدمات تقريباً؛ مما يترتب عليه كثير من المشاكل على العملية الإدارية والتتظيمية.

8. قلة الأوقات المخصصة لزيارة المقبرة،

وضيق الددة نتيجة لعمليات الفتح والإغلاق وإخلاء

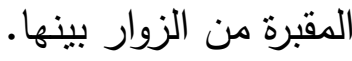

9. وجود مدخل ومخرج واحد لزيارة المقبرة

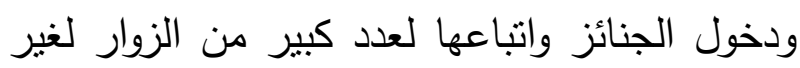

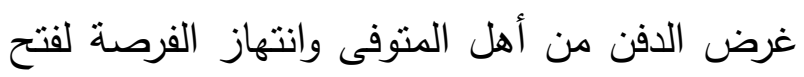

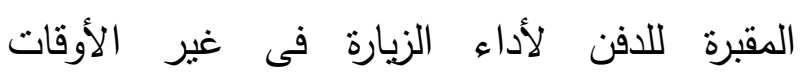
المخصصة للزيارة.

10.غالبية الزوار من جنسيات مختلفة من

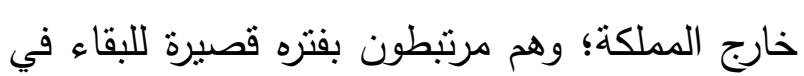

\section{7 - خلاصة تحليل الوضع الراهن}

فيما سبق تم استعراض الوضع الراهن لمقبرة

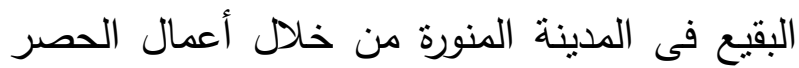

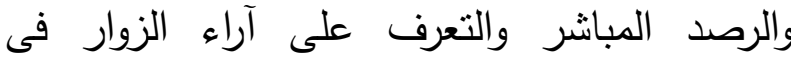

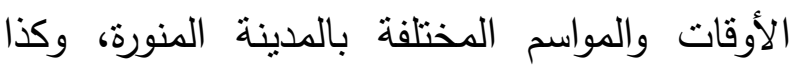
تحديد أهم المشاكل المرتبطة بالوضع الراهن وأماكن

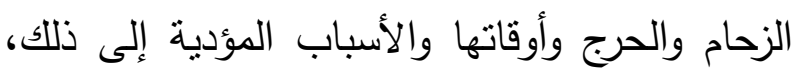
والتى يجب أن تؤخذ فى الاعتبار عند وضع بدائل والي

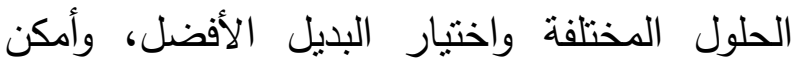
تلخيص المشاكل المرتبطة بزيارة البقيع بالمدينة

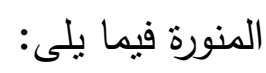
1. شدة الازدحام وتباطؤ الحركة مما يزيد

الوقت والجهد المبذولين ناهيك، عن أن ذلك يحدث التردئ

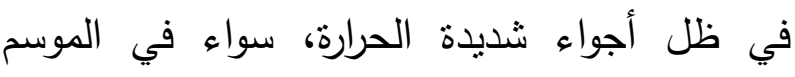

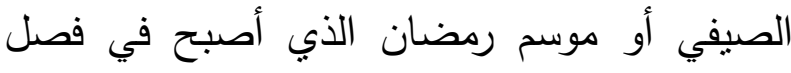
الصبف (خلال السنة التي أجريت بها الدراسة).

2. طول المدة اللازمة للزيارة نتيجة لتكدس

الزوار والازدحام في المسارات المخصصة لذلك.

3. عدم توفر تجهيزات خاصة بالزوار من

كبار السن وذوى الاحتياجات الخاصة، ويترتب على بلى ذللك عدم تمكن الكثير من زوار المدينة المنورة والمسجد النبوى الثريف من كبار السن وذوى الاحتياجات الخاصة من زيارة مقبرة البقيع والدعاء لأهله اقتداء بسنة النبى النئ. 


$$
\begin{aligned}
& \text { لتحسين وتهيئة زيارة مقبرة البقيع التي تحقق }
\end{aligned}
$$

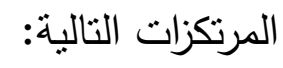

$$
\begin{aligned}
& \text { 1) شرعية واكتمال أداء زوار البقيع لزيارتهم } \\
& \text { لكامل المقبرة فى أمان وسهولة ويسر . } \\
& \text { 2) تسهيل الدخول والخروج أثثاء الزيارة، } \\
& \text { ومنع تضاد الحركة وتوفير الممرات المناسبة. } \\
& \text { 3) إتاحة الفرصة لكبار السن وأصحاب } \\
& \text { الاحتياجات الخاصة للزيارة، بنوفير التجهيزات } \\
& \text { الخاصة لهم. } \\
& \text { 4) وضع الإرشادات والمعلومات الكافية فى } \\
& \text { المكان المناسب للزوار، فيما يتعلق بتاريخ المقبرة } \\
& \text { والتعريف بآداب الزبارة، والدعاء للموتى، وتبيان } \\
& \text { التصرفات الخاطئة التي يجب تجنبها. } \\
& \text { المنوط بهم تتظيم الزيارة بالمقبرة. } \\
& \text { والجهات المختلفة التي يوجد بها. }
\end{aligned}
$$

\section{1-8}

يكون مسار الزيارة على كامل محيط المقبرة

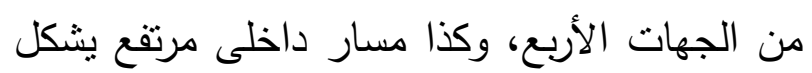

المدينة، والسبب الرئيس لزيارتهم هو إحياء السنة

النبوية، كما أن معدل الوقت الذي يقضونه في الزيارة في حدود 30 دقيقة تقريباً.

11. على الرغم من قيام بعض الزوار بالزيارة

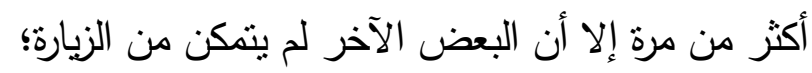

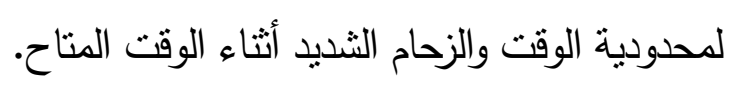

12.عدم رضى الزوار عن الوضع الراهن

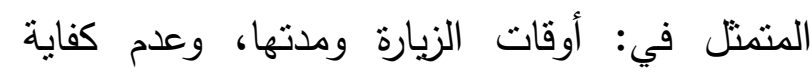

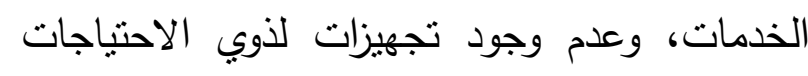

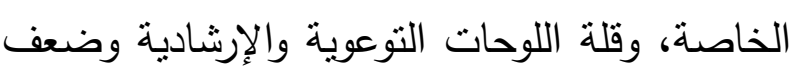

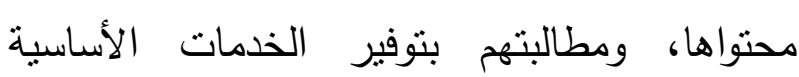
وخصوصاً مشارب المياه، ومنطلبات كبار السن لونئن

$$
\text { وذوي الاحتياحات الخاصة. }
$$

13.تبين أن الجنسيات الأفغانية والباكستانية

والمصرية الأكثر زيارة، إذ تجاوز عدد مرات الزيارة خمس مرات، وفي نفس الوقت عدم رضاهم عن مدة الده

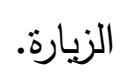

14.أثّر المستوى العلمي في خفض عدد مرات الزيارة، بحيث انخفض العدد مع ارتفاع المستوى علي هري

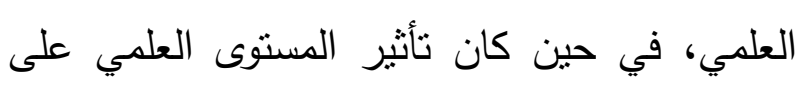
مستوى الرضى عن مدة الزيارة عالياً. 8- الحلول والمقترحات

من خلال ما سبق عرضه، والمتضمن الوضع

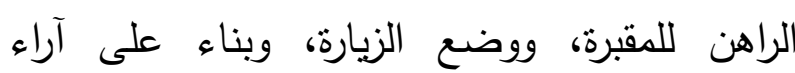

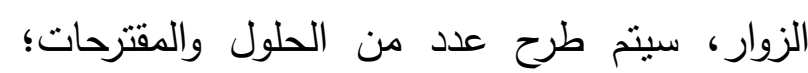




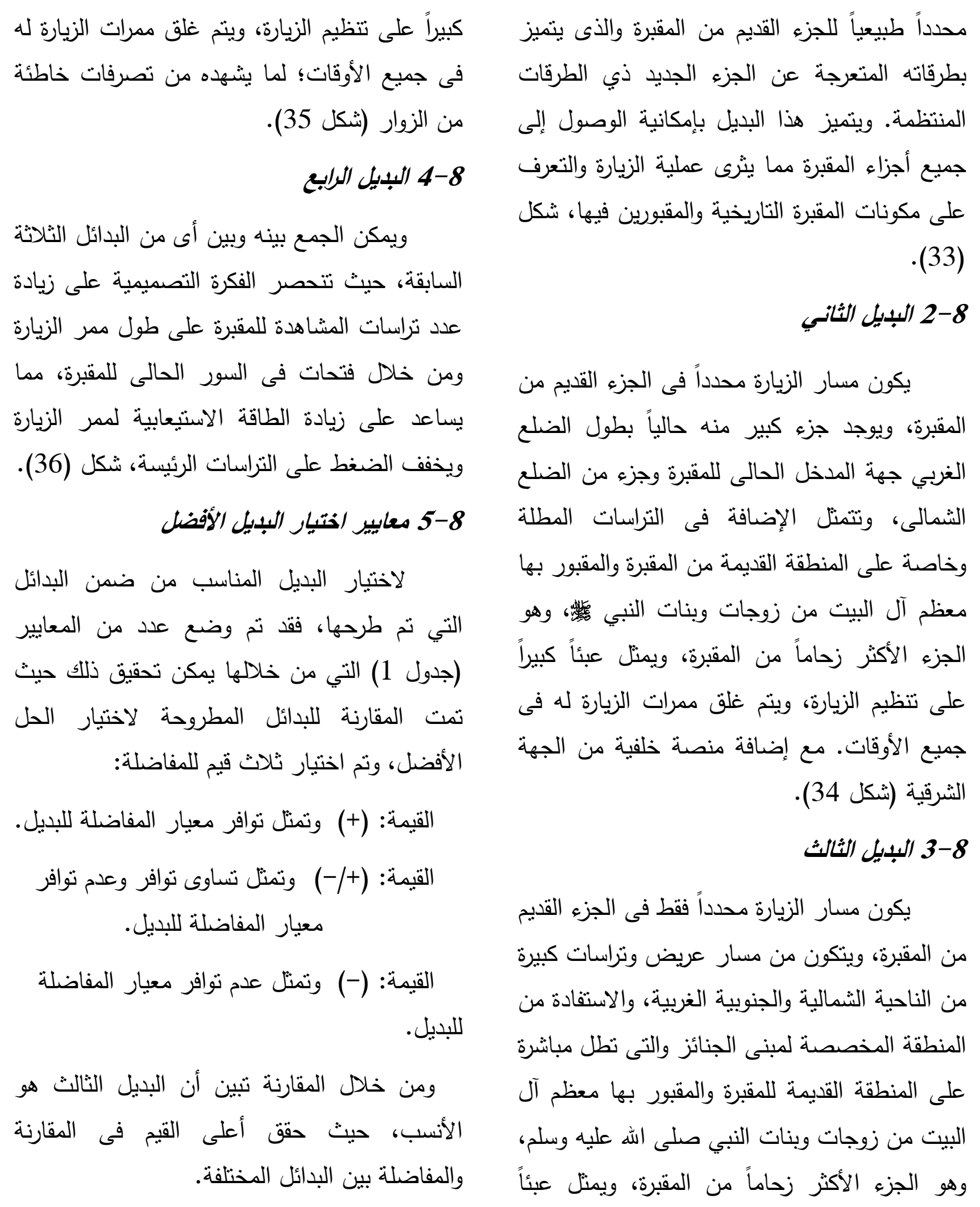




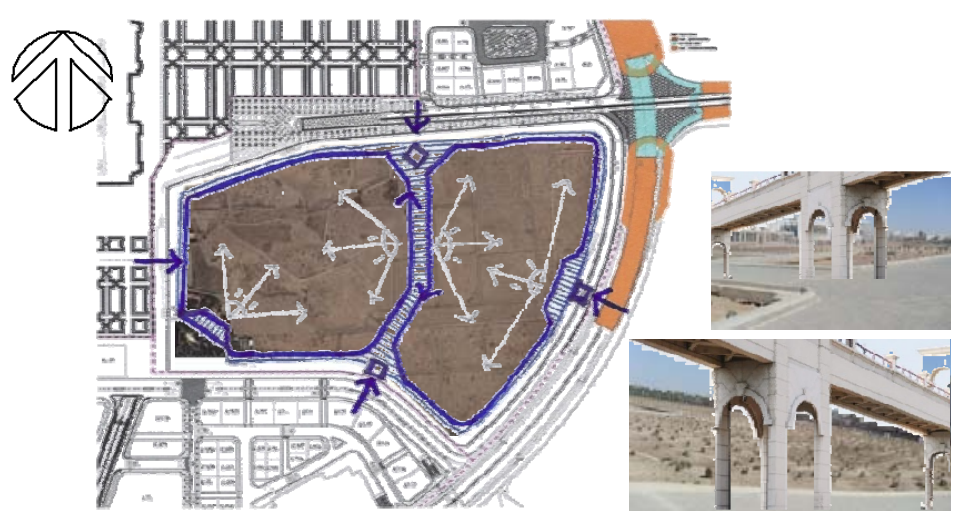

شكل 33. البديل الأول: يوضح مسار الزيارة على كامل محيط المقبرة ويمر داخلها.

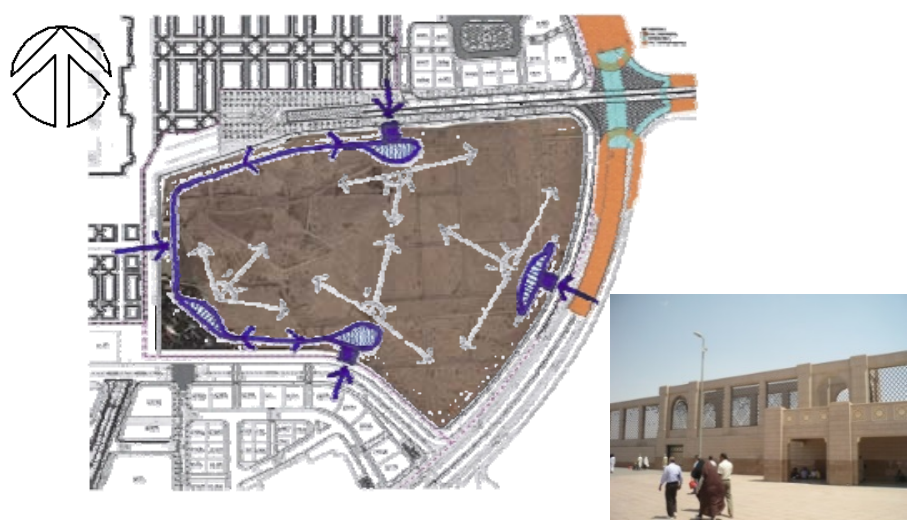

شكل 34. البديل الثانى: التركيز على زيارة جميع أجزاء المقبرة بدون أعمال إنثائية كبيرة.

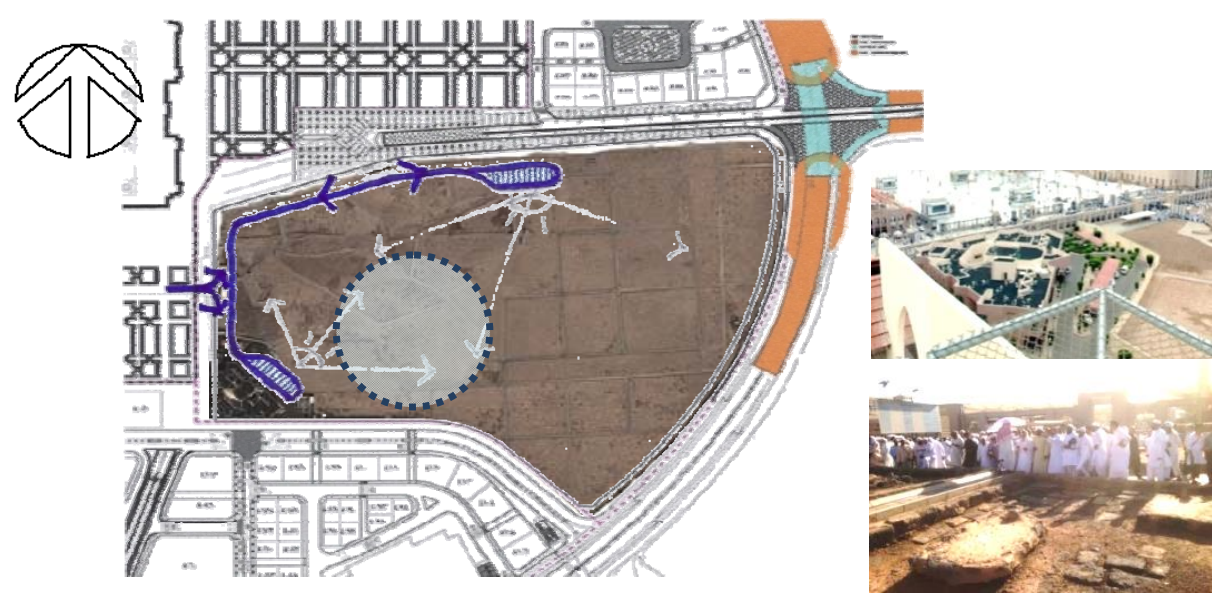

شكل 35. البديل الثالث ويكون التركيز للزيارة فيه على المنطقة القديمة من المقبرة. 


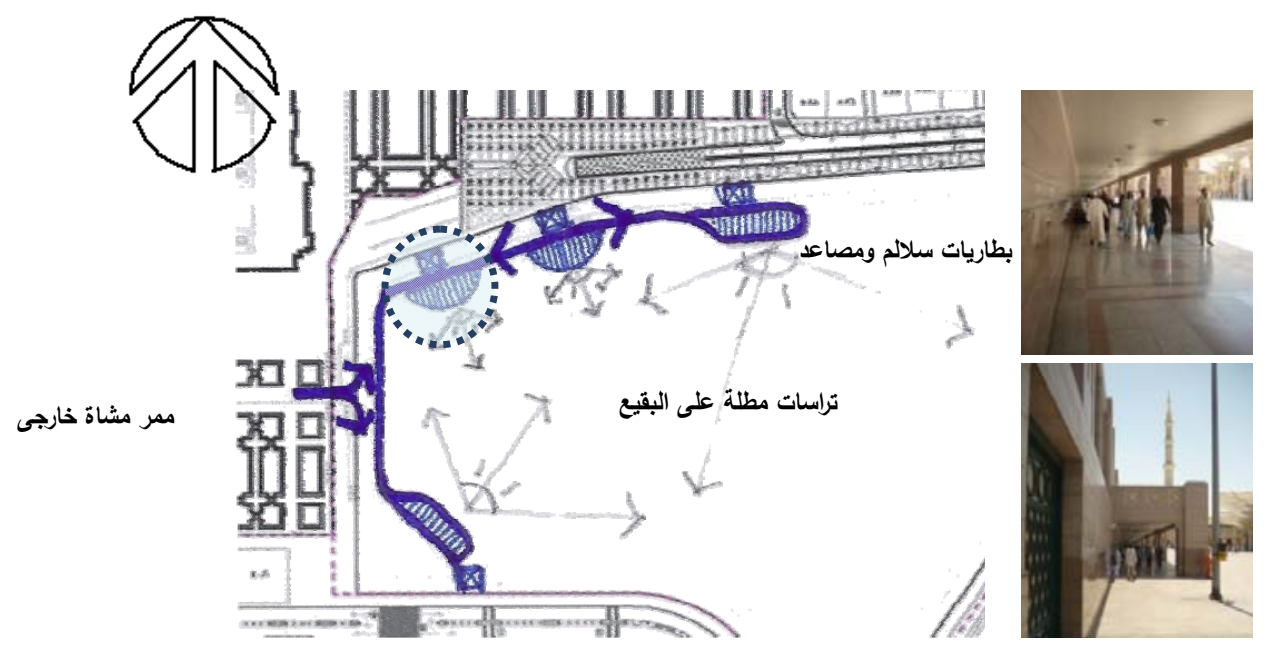

شكل 36. البديل الرابع بزيادة عدد تراسات المشاهدة للمقبرة على طول ممر الزيارة.

جدول 1. معايير مقارنة البدائل.

\begin{tabular}{|c|c|c|c|c|}
\hline البديل الرابع & البديل الثالث & البديل الثانى & البديل الأول & أوجه المقارنة \\
\hline+ & + & + & + & حل جذرى \\
\hline+ & + & + & + & الاتفاق مع الأهداف المرجوة \\
\hline+ & + & + & $-1+$ & الاتفاق مع القيود المفروضة \\
\hline+ & + & + & $-1+$ & الإمكانية الفنية \\
\hline+ & + & + & $-1+$ & عدم التأثير السلبي على البيئة التراثية \\
\hline$-/+$ & + & $-/+$ & $-/+$ & قلة حجم الأعمال الإنشائية \\
\hline+ & + & + & + & التأثير على البيئة المحيطة \\
\hline+ & + & + & + & الأمان فى التثغيل \\
\hline+ & + & + & + & زيادة الطاقة الاستيعابية \\
\hline+ & + & + & + & جودة مستوى الخدمة المقدمة \\
\hline+ & + & + & + & قلة الاحتباج إلى القوى العاملة \\
\hline+ & + & + & + & درجة المهارة والتندريب \\
\hline$* * *$ & ***** & $* * *$ & $* *$ & الأفضلية \\
\hline
\end{tabular}




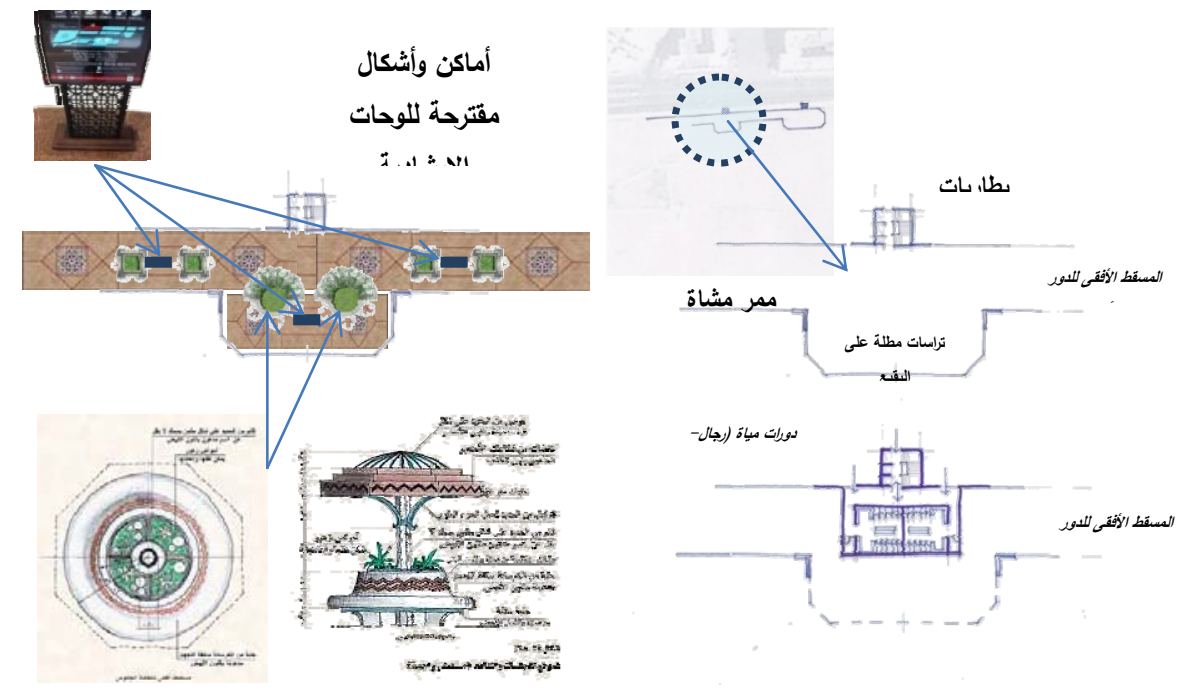

شكل 37. المسقط الأفقى لممر الزيارة المقترح يوضح بعض التفاصيل والتجهيزات الخاصة.

والبدائل التي قدمتها الدراسة لتهيئة وتحسين زيارة مقبرة البقيع وتوفير متطلبات الزوار والتي تم اختيار أنسبها، توصي الدراسة بما يلي: " سرعة تتفيذ المقترح الذي تم اختياره لتهيئة وتحسين زيارة البقيع وتزويده بجميع العناصر

$$
\text { اللازمة. }
$$

وضع خطة تشغيلية متكاملة لتهيئة وتحسين

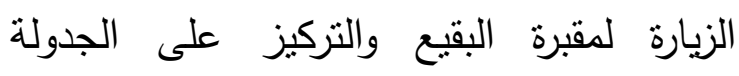
الزمنية. تكثيف التدريب للقائمين على تنظيم الزيارة من رجال الأمن ومنسوبى الهيئة. تفعيل الدور التوعوي والإرشادي للزوار خارج الأنة المقبرة، وفي المقبرة وفي بلادهم. توفير شاشات رقمية تقدم مواضيع متعلقة بتاريخ المقبرة، وبآداب الزيارة بجميع اللغات.
6-8

ويوضح الثكل (37) تفاصيل المساقط الأفقية لممر الزيارة، وبطاريات السلالم والمصاعد للوصول

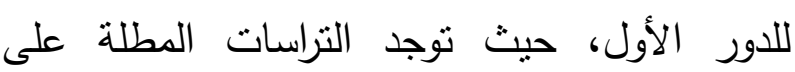

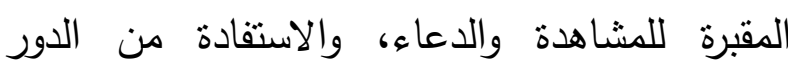
الأرضى لتوفير الخدمات اللازمة للزوار (دورات مياه - مراكز صحية - توعية وإرشاد - محلات ... الخ) سواء لزوار المقبرة أو المنطقة المركزية للمدينة المنورة.

\section{0- الخلاصة والتوصيات}

من خلا ما سبق يتضح أن مقبرة البقيع

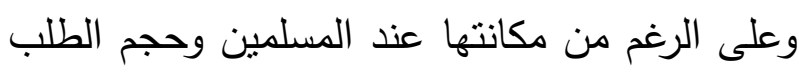

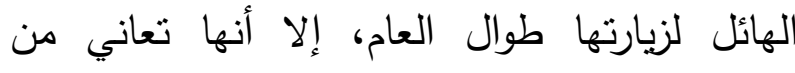
صعوبة في الزيارة، وتدنٍ في مستوى الخدمات، وبناء على ما بينته دراسة الوضع الراهن وآراء الزوار 
النبوية الثريفة وتفعيلاً لمناطق التراث، مجلة البحوث

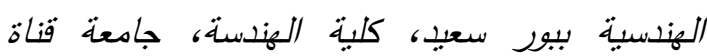
السوبس، بور سعيد، مصر . حافظ، على (1417هـ) " فصول من تاريخ الددينة"، شركة المدينة المنورة للطباعة والنشر ، جدة، الممملكة العربية السعودية . مكي، محمد شوقي (1405هـ) 'أطلس المدينة

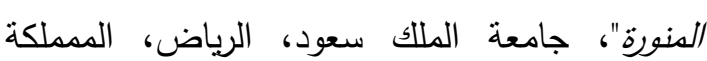

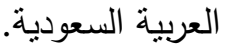

هيئة تطوير المدينة المنورة (1433) المخطط

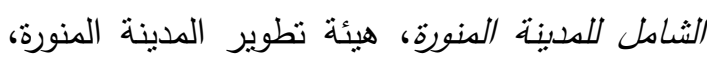
المدينة المنورة، الممملكة العربية السعودية. عبدالغني، محمد إلياس (1416هـ). "تاريخ المسجد

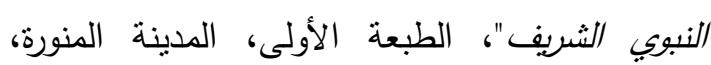
الممملكة العربية السعودية. الأنصاري، ناجي (1416هـ) "عمارة وتوسعة الصسجد النبوي الثربف عبر التاربخ"، الطبعة الأولى، نادي

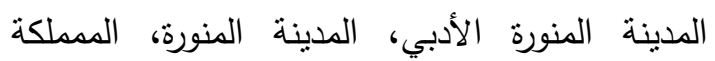

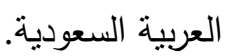

النهرواني، قطب الدين محمد بن علاء الدين

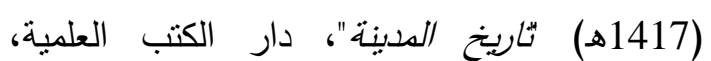
بيروت- لبنان.

D.E.T.R (1998) Design in the Planning System. Department of the Environment, Transport and the Regions. London, UK.

http://www.governor.ny.gov/sites/governor.ny.gov/file s/archive/governor_files/images/TripleCurvePerspectiv e.jpg, visited online on th web on 1 Feb. 2016 at 7:35 p.m. www.saratogaassociates.com/amsterdampedestrian-bridge, visited online on th web on $1 \mathrm{Feb}$. 2016 at 7:35 p.m.
اعتماد الأنماط العمرانية التي تتناسب مع النمط

$$
\text { التقليدي للمدينة المنورة. }
$$

• اختيار مواد التشجير التي تتناسب مع بيئة

$$
\text { المدينة المنورة. }
$$

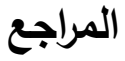

الخياري، أحمد ياسين أحمد، تعليق وإيضاح: عبيداله [8) ] كردي (1990) تاريخ معالم الددينة الدنورة قديبًا وحديًًا" ، نادي المدينة المنورة الأدبي، المدينة المنورة، لـانة الممملكة العربية السعودية.

الرفاعي، صالح بن حامد بن سعد (1413هـ) الأحاديث الواردة في فضائل المدينة"، رسالة دكتوراه من الجامعة الإسلايَّة بالمدينة الهنورة، نشر مركز خدمة السنة والسيرة بالمدينة المنورة، الممملكة العربية

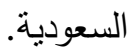

البلر، عبدالباسط (1414هـ) التاريخ الثامل للمدينة

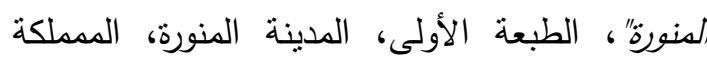
العربية السعودية . الأنصاري، عبدالقدوس (1420هـ)،" آثار المدينة المنورة"، المكتبة العلمية بالمدينة المنورة، الممملكة العربية السعودية. البلقاسي، محمد إبراهيم (1433هـ) الطابع المعماري والعدراني للمنطقة المركزية بالمدينة المنورة ودوره في

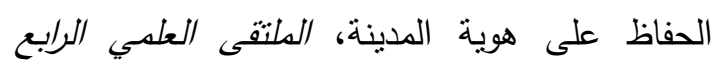
لأبحاث المدينة المنورة، معة خادم الحرمبن الثريفين لأبحاث الحج والعدة، جامعة أم القرى، المدينة المنورة، المدملكة العربية السعودية. إدريس، محمد عبد الله (1424هـ) دراسة إنشاء طريق

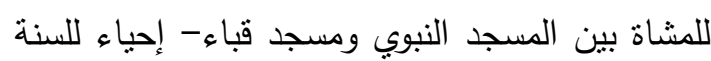


Facilitating and Improvement of al-Baqia Cemetery Visit, Al Madinah Almonawara

Mohammed A. Edrees

The Custodian of the Two Holy Mosques Institute for Hajj and Umrah Researches

Umm Al-Qura University- Makkah Al Mukarramah, Saudi Arabia

Edreesma2@hotmail.com

Abstract. Al-Baqia cemetery is considered the main cemetery for residents of Madinah, and it houses the remains of thousands upon thousands of those who had lived and died in Madinah. At the forefront of those buried in it are the prophet's companions and his wives. The cemetery is open twice a day for visitors, after fajr and asr prayers for a very short time and only for men. With the increasing number of visitors and the problems associated with these visits, arose a need for improvement and finding solutions and alternatives to prepare for and facilitate visiting the cemetery, and also decrease the crowdedness during those short visits. This study, which is based on literature review and collected field data aims to identify the existing situation of the cemetery, in addition to which is based on liter interviewing a samper visiting cemeteries in Islan and viewing pans, due to their importance of those paths. Analysis of collected data revealed several results through which the study was able to present four suggestions and after evaluating them based on certain criteria, the best alternative was chosen, the study ends with a conclusion and recommendations.

Keyword: Al Madinah Almonawara, al-Baqia, Visit, Facilitating, Improvement. 
